(ㄷ 2020, The Authors. Published by FASS Inc. and Elsevier Inc. on behalf of the American Dairy Science Association ${ }^{\circledR}$.

This is an open access article under the CC BY-NC-ND license (http://creativecommons.org/licenses/by-nc-nd/4.0/).

\title{
Meta-analysis of the effects of supplemental rumen-protected choline during the transition period on performance and health of parous dairy cows
}

\author{
U. Arshad, M. G. Zenobi, C. R. Staples, (1) and J. E. P. Santos* (i) \\ Department of Animal Sciences, DH Barron Reproductive and Perinatal Biology Research Program, University of Florida, Gainesville 32611
}

\begin{abstract}
The objectives were to use meta-analytic methods to determine the effects of amount of supplemental choline ion as rumen-protected choline (RPC) starting prepartum on production and health of dairy cows. The literature was systematically reviewed and 21 experiments, with up to 66 treatment means and 1,313 prepartum parous cows, were included. All experiments had a treatment with no supplemental choline $(0 \mathrm{~g} / \mathrm{d}$; $\mathrm{n}=30$ treatment means), and the amount of choline ion supplemented to treated cows ranged from 5.6 to $25.2 \mathrm{~g} / \mathrm{d}$ ( $\mathrm{n}=36$ treatment means). Duration of preand postpartum feeding of RPC averaged ( \pm standard deviation) $22.0 \pm 6.0$ and $57.5 \pm 42.2 \mathrm{~d}$, respectively. Data collected included the ingredient composition and chemical analyses of pre- and postpartum diets, amount of choline ion supplemented, number of cows per treatment, frequency of health events, and the least squares means and respective standard error of the means for production responses, liver composition, and blood parameters. The concentrations of net energy for lactation and metabolizable amino acids and protein (MP) in pre- and postpartum diets were predicted for each treatment mean using National Research Council (2001). Mixed model meta-analysis was conducted including the random effect of experiment and weighting by the inverse of the standard error of the means squared. Increasing supplementation of choline ion during transition linearly increased pre- $(\beta=0.0184 \pm$ $0.00425)$ and postpartum dry matter intake $(\beta=0.0378$ $\pm 0.00974)$, and yields of milk $(\beta=0.436 \pm 0.112)$, energy-corrected milk (ECM; $\beta=0.422 \pm 0.0992)$, fat $(\beta=0.00555 \pm 0.000793)$, and protein $(\beta=0.0138 \pm$ $0.00378)$. Nevertheless, an interaction between choline and postpartum metabolizable methionine as a percent of MP (METMPPo) was observed for yields of milk, ECM, and protein because as METMPPo increased, the positive response to choline on yields of milk, ECM,
\end{abstract}

Received April 22, 2019.

Accepted September 9, 2019.

*Corresponding author: jepsantos@ufl.edu and protein decreased. Supplementing choline during transition tended to reduce the risks of retained placenta and mastitis, but it had no effect on metritis, milk fever, displaced abomasum and ketosis, or the concentration of triacylglycerol in the hepatic tissue postpartum. The median amount of choline ion supplemented was $12.9 \mathrm{~g} / \mathrm{d}$ and responses in postpartum dry matter intake and yields of milk, ECM, fat, and protein to that amount of supplementation were $0.5,1.6,1.7$, 0.07 , and $0.05 \mathrm{~kg} / \mathrm{d}$, respectively. No interactions were observed between supplemental choline and prepartum dietary net energy for lactation or metabolizable methionine as a percent of MP. Collectively, feeding RPC during the transition period improves performance in parous cows. Increases in yields of milk and milk components were observed in spite of pre- and postpartum diets, although the increments in milk, ECM, and protein yields with supplementing choline decreased as the concentration of methionine in postpartum diets increased. The optimum dose of choline ion was not detected, but likely it is more than the $12.9 \mathrm{~g} / \mathrm{d}$ fed in most experiments evaluated in the current metaanalysis. Finally, the meta-analysis identified lack of sufficient data to understand the role of supplemental choline in nulliparous cows.

Key words: choline, health, milk yield, transition cow

\section{INTRODUCTION}

Choline is a known essential nutrient in diets of monogastrics; in particular, it is required for synthesis of essential membrane phospholipids, plays a role in the 1-C metabolism, and acts as a precursor for synthesis of acetylcholine (Zeisel and Da Costa, 2009). An important aspect of choline is its roles on lipid intermediary metabolism, and choline deficiency results in fatty liver presumably because of less biosynthesis of phosphatidylcholine that impairs the export of hepatic triacylglycerols as very low density lipoprotein (Yao and Vance, 1988), thereby resulting in liver steatosis. In ruminants, however, almost all dietary choline is degraded by ruminal microbes (Sharma and Erdman, 1989a), which precludes proper dose titration experi- 
ments and requires choline to be supplemented in a rumen-protected form.

Dairy cows in the last weeks of gestation and first few weeks of lactation are prone to negative nutrient balance, which induces extensive catabolism of fat depots and can result in up to $50 \%$ developing moderate to severe fatty liver (Bobe et al., 2004). It is thought that fatty liver in periparturient dairy cows is the result of combined extensive uptake of fatty acids by the liver with resulting reesterification to triacylglycerols because of the slow rate of lipoprotein export by the bovine liver (Drackley, 1999). Reynolds et al. (2003) showed an extensive increase in hepatic extraction of fatty acids from $19 \mathrm{~d}$ before to $11 \mathrm{~d}$ after calving, a difference of approximately $2.28 \mathrm{~mol} / \mathrm{d}$. This increase likely reflects the change in lipolysis with the onset of lactation, which would predispose cows to fatty liver. Cows experiencing hepatic lipidosis have compromised health such as increased risk of ketosis and displaced abomasum and reduced productive performance (Drackley, 1999; Bobe et al., 2004). At the same time that cows undergo negative nutrient balance, the concentrations of choline metabolites in plasma are at their lowest during the first weeks of lactation (Artegoitia et al., 2014; Imhasly et al., 2015), and supplementing rumen-protected choline (RPC) increased plasma concentrations of choline metabolites in prepartum cows (Zenobi et al., 2018b). Improving choline status prepartum has the potential to reduce the risk of fatty liver (Cooke et al., 2007; Zenobi et al., 2018b) and improve health and lactation performance postpartum (Lima et al., 2012).

Numerous experiments have been conducted to determine the effect of supplementation of RPC in different forms and doses and under distinct dietary manipulations on postpartum performance (Hartwell et al., 2000; Zhou et al., 2016; Zenobi et al., 2018a). In general, supplementing transition cows with RPC increases yields of milk, fat and ECM (Baldi and Pinotti, 2006; Sun et al., 2016; Zenobi et al., 2018a), although responses have not always been consistent (Hartwell et al., 2000; Zhou et al., 2016). Nevertheless, little is known about the optimum dose of choline ion fed as RPC on postpartum performance. Furthermore, the effect of RPC on risk of health disorders is mostly unknown because the majority of experiments had restrictions on sample size to evaluate disease incidence. Finally, because both choline and methionine participate in the 1-C metabolism, it is possible that responses to choline are dependent on the supply of methionine. One approach to address some of these issues is to use meta-analytic methods in an attempt to integrate findings from results of individual experiments available in the scientific literature (Lean et al., 2009). The hypothesis of the present study was that supplementation of choline ion as RPC during the transition period would improve the postpartum production and reduce incidence of health problems in dairy cows. A second of hypothesis was that using mixed models meta-analysis would result in identification of an optimum amount of choline ion to be fed to cows to improve productive performance postpartum. Therefore, the objectives of the study were to use data from the published literature, in which the supplementation of RPC started prepartum, to evaluate the effects on production and health of dairy cows. An additional objective was to identify an optimal dose of choline ion fed as RPC and whether responses to RPC depend on prepartum dietary energy content and preand postpartum supplies of metabolizable methionine.

\section{MATERIALS AND METHODS}

\section{Search of the Published Literature}

A comprehensive search of the literature published in the English language from 1984 to 2018 was conducted to identify experiments with transition dairy cows in which diets were supplemented with RPC starting prepartum.

The literature search included 3 search engines: the US National Library of Medicine and National Institutes of Health through PubMed (http://www.ncbi.nlm .nih.gov/pubmed), USDA National Agriculture Library through Agricola (https://agricola.nal.usda.gov), and Web of Science (http://apps.webofknowledge.com). In addition, searches were also conducted on proceedings of the Joint Annual Meeting of the American Dairy Science Association and American Society of Animal Science, database of theses and dissertations (http:/ /www.proquest.com/), and on websites of animal nutrition journals (http://www.publish.csiro.au/). The search was conducted between September and December of 2018 using the terms with a set of key words in all searches: choline dairy cow, choline transition cow, rumen-protected choline cow, rumen-protected choline transition cow, reashure cow, and reashure transition cow. The key word reashure was used because it was identified as the most common commercial product containing RPC fed to dairy cows. Moreover, additional requests were made to individual authors of manuscripts to identify data that might have been collected, but not reported in the published paper. Authors of dissertations were contacted to have access to the complete set of responses that might have not been presented or to clarify if similar data originated from unique experiments or from the same experiment presented more than once in a dissertation. 


\section{Inclusion and Exclusion Criteria}

All published literature was screened using standardized criteria. Experiments with individually or groupfed dairy cows in which experimental unit was clearly defined (cow or pen) and supplementation of RPC started prepartum were considered eligible. Moreover, experiments had to be either completely randomized designs or randomized block designs and they had to have a control group in which no RPC was supplemented. The ingredient composition of the pre- and postpartum diets fed had to be reported. The nutrient content of the diets was collected, and authors were contacted whenever it was not described in the manuscript. Experiments had to report least squares means (LSM) and standard error of the means (SEM) of individual treatments for the responses of interest. The RPC product could have been incorporated into the TMR or fed as top dress. The experiments in which choline was not fed as a protected source, fed only during the postpartum period, or experiments in which cows were fed restricted were all excluded from the database.

\section{Experiments Included}

Supplemental Figure S1 (https://doi.org/10.3168/ jds.2019-16842) depicts a Prisma diagram (Moher et al., 2009) of the flow of data collection for the metaanalysis. After the initial search and screening, 48 publications, including multiple experiments, were assessed for eligibility. From those, 28 experiments/manuscripts were excluded for the following reasons: companion manuscripts reporting data not relevant to the metaanalysis $(\mathrm{n}=9), 6$ manuscripts that did not report the animal responses of interest, 4 manuscripts with experiments in which treatments were applied only postpartum, 3 manuscripts in which choline was supplemented blended with other vitamins or betaine or AA, 2 manuscripts in which choline was supplemented to dry cows subjected to feed restriction, 2 manuscripts published in the German language (authors were contacted, but no response), 1 manuscript with only nulliparous cows, and 1 abstract of an experiment subsequently published as a full manuscript. Only 3 experiments were conducted either with only nulliparous cows or reported data separately for nulliparous from parous cows. In those experiments, authors did not report all responses of interest. Therefore, because of the paucity of data for nulliparous, it was decided that only experiments and treatment means including parous cows were eligible for inclusion in the meta-analysis. Finally, a total 20 manuscripts reporting data from 21 experiments with up to 66 treatment means were used in the meta-analysis. A list of the experiments included in the meta-analysis is depicted in Supplemental Table S1 (https://doi.org/10.3168/jds.2019-16842). References of the manuscripts used in the meta-analysis are listed in the Supplemental File (https://doi.org/10.3168/jds .2019-16842).

\section{Data Extraction}

Individual treatment LSM and SEM were extracted from tables or figures. Values presented in figures were extracted using an image extraction software (https: //automeris.io/WebPlotDigitizer/) as previously reported (Santos et al., 2019).

Data collected for each treatment within experiment included number of cows, duration of treatment during pre- and postpartum period, milking frequency, ingredient composition of diets fed prepartum, the nutrient content of ingredients and of the diets fed pre- and postpartum, and number of days of measurements postpartum. For treatments in which RPC was supplemented, the information on the product used was collected to calculate the amount of choline ion fed. Choline ion was calculated based on the concentration of choline chloride in the product and the molar proportion of choline ion in choline chloride $(74.6 \%)$. This was done to be able to model the effect of choline ion fed as RPC on the responses of interest. The suggested bioavailability of choline in the RPC products used in the different experiments was not taken into account because of the lack of a standard method to estimate choline bioavailability in ruminants for rumen-protected products.

All prepartum diets were entered in the NRC (2001) software using the respective chemical analysis of ingredients whenever available. When chemical analysis of ingredients was unavailable, then the library of NRC (2001) was used to match as close as possible the final chemical composition of the TMR described in the experiment. Moreover, authors of experiments used in the meta-analysis were contacted to clarify details about the diets fed prepartum whenever enough information was not provided in the manuscript. Information about parity group of cows in the prepartum period, BW $(\mathrm{kg})$, BCS (1 to 5$)$, and DMI (kg/d) were used for each treatment diet to estimate the contents and intakes of $\mathrm{NE}_{\mathrm{L}}$ (Mcal/kg), CP (\%), MP (\%), and metabolizable EAA of pre- and postpartum diets. The percentage of the prepartum diet DM as MP was calculated for each treatment mean using the predicted MP supply and the observed DMI measured pre- and postpartum for that treatment mean. The ratio of metabolizable methionine relative to the MP was calculated for each treatment mean based on the respective supplies of MP and metabolizable methionine. The rationale for using these 
relative values was to avoid collinearity of predictors because supply of MP or AA are highly correlated, and both are related to pre- and postpartum DMI.

Responses collected for the prepartum period included DMI (kg/d), BW (kg), BCS (1 to 5), concentrations of liver triacylglycerol (\% wet basis), and blood concentrations of glucose $(\mathrm{m} M)$, BHB $(\mathrm{m} M)$, and fatty acids $(\mathrm{m} M)$. Responses collected for the postpartum period included DMI, yields of milk $(\mathrm{kg} / \mathrm{d})$, ECM $(\mathrm{kg} / \mathrm{d})$, fat $(\mathrm{kg} / \mathrm{d})$, protein $(\mathrm{kg} / \mathrm{d})$, and lactose $(\mathrm{kg} / \mathrm{d})$, concentrations of fat (\%), protein (\%), and lactose (\%) in milk, SCS, ECM/DMI, BW, BCS, concentrations of liver triacylglycerol and glycogen (\% wet basis), blood concentrations of glucose, BHB, and fatty acids, and incidence of retained placenta, metritis, mastitis, milk fever, displaced abomasum, and ketosis. Some experiments did not report yields of milk components or ECM or ECM/DMI. Authors were contacted to provide the LSM and respective SEM. Whenever the values were not obtained directly from authors, then the treatment means were calculated (e.g., protein yield $=$ LSM for milk yield $\times$ LSM for milk protein \%). The ECM was calculated using the formula $\mathrm{ECM}=[($ milk yield $\times$ $0.327)+($ fat yield $\times 12.95)+($ protein yield $\times 7.2)]$ (Orth, 1992). An approximation was used to calculate the SE whenever it was not available for yields of milk components or ECM. For example,

$$
\begin{gathered}
\text { SE for protein yield }=\text { protein yield } \\
\times \sqrt{\left(\frac{\mathrm{SE} \mathrm{milk}}{\mathrm{LSM} \text { milk }}\right)^{2}+\left(\frac{\mathrm{SE} \text { protein } \%}{\text { LSM protein } \%}\right)^{2}} \text {, or } \\
\mathrm{SE} \mathrm{ECM}=(\mathrm{SE} \text { milk } \times 0.327) \\
+(\mathrm{SE} \text { fat yield } \times 12.95)+(\mathrm{SE} \text { protein yield } \times 7.2) .
\end{gathered}
$$

Responses from different publications were standardized to the same unit using the metric system and concentrations of analytes in blood were converted to millimolar.

Data were transferred to Excel spreadsheets (Microsoft Corp., Redmond, WA) and reviewed by 2 people to ensure information collected was accurately transcribed from the manuscripts into the spreadsheets before statistical analyses.

\section{Statistical Analysis}

Choline as a Continuous Variable in Statistical Models. Intake of DM, BW, BCS, yields of milk and milk components, SCS, feed efficiency, and concentrations of metabolites in blood were all analyzed with choline as a continuous variable in the statistical models.

Responses were analyzed by the MIXED procedure of SAS (version 9.4, SAS/STAT, SAS Institute Inc., Cary, NC). All mixed models included the random effect of experiment and responses were weighted using the WEIGHT statement in SAS (SAS/STAT, SAS Institute Inc.) with the inverse of SEM squared (1/ $\mathrm{SEM}^{2}$ ) that was centered for each response analyzed as suggested by Wang and Bushman (1999). Statistical models were built following the general matrix notation of a mixed model:

$$
\mathrm{y}=\mathbf{X} \boldsymbol{\beta}+\mathbf{Z}_{\boldsymbol{\gamma}}+\varepsilon,
$$

where $\mathbf{y}$ is the response analyzed, $\mathbf{X}$ is the design matrix corresponding to the fixed effects and the associated vector $\boldsymbol{\beta}$ of the regression coefficients, $\mathbf{Z}$ is the matrix for the random effects with the vector $\gamma$ of their associated coefficients; and $\varepsilon$ is the random error assumed to be normally distributed with mean 0 and nonzero variance-covariance matrix.

The key predictor of interest for statistical models was intake of choline ion, which was used as a fixed parameter in the models fitting linear and quadratic effects. The rationale for using choline as a continuous variable was to attempt to model the optimum amount ingested when sufficient treatment means were available and the amounts of choline supplemented varied substantially.

Univariable analyses including a single fixed effect and the random effect of experiment were performed to understand the association between each predictor and the response analyzed. Predictors were first inspected for multicollinearity for every response analyzed using collinearity analysis (Collin) in the REG prcedure of SAS (SAS/STAT, SAS Institute Inc.) and inspecting condition index, tolerance, and variance inflation factor (VIF). For all responses evaluated, there was no indication of multicollinearity based on condition index less than 80 and VIF smaller than 3.0 in all final multivariable models as previously described. Subsequently, for all responses analyzed, multivariable models were built.

For the analyses using choline ion as a continuous variable, the fixed effects considered for the statistical models included the linear and quadratic effects of choline ion intake $(\mathrm{g} / \mathrm{d})$, dietary $\mathrm{NE}_{\mathrm{L}}$ content prepartum $\left(\mathbf{N E}_{\mathbf{L}} \mathbf{P r}\right)$, metabolizable methionine as percentage of MP pre- (METMPPr) and postpartum (METMPPo), and interactions between choline ion intake and $\mathrm{NE}_{\mathrm{L}} \mathrm{Pr}, \mathrm{METMPPr}$, and METMPPo. A backward elimination procedure was applied and at each step with removal of model parameters if $P>0.10$ with 
the highest order parameters (interactions or quadratic effect of choline) removed from the model sequentially according to the largest $P$-value. Each model was rerun until interactions, individual predictors, or both resulted in $P<0.10$ with improved model fit based on a reduced value for the Akaike's information criterion. At each iteration, VIF and distribution of residuals and homogeneity of variance were inspected to avoid collinearity and to certify that data fit the assumptions of normality. Residual plots were visually inspected for the distribution and it was accepted that assumptions of normality were not infringed upon when at least $95 \%$ of the studentized residuals were within \pm 2 standard deviations. The INFLUENCE statement in SAS (SAS/ STAT, SAS Institute Inc.) was used to obtain potential influential points with high leverage or large Cook's D. Goodness-of-fit statistics for distribution of residuals were evaluated in all analyses. Whenever the null hypothesis was rejected $(P<0.05)$, then the Box-Cox power transformation was used to determine the proper transformation of data before statistical analyses (Piepho, 2009). If final models were the same and significance and interpretation of the data did not change with transformation, then the analysis was carried out on the original scale of the data.

Whenever all interactions with choline and covariates $\left(\mathrm{NE}_{\mathrm{L}} \mathrm{Pr}, \mathrm{METMPPr}\right.$, and METMPPo) resulted in $P>$ 0.10 , then the final models forced the linear effect of choline ion, and the random effect of experiment, with weighting by the centered value of the inverse of the SEM squared. For all final models, variance inflation was re-assessed to ensure that parameters remaining in the model resulted in low VIF and distribution of residuals and homogeneity of variance were evaluated. Once a final model was selected, the random slope of choline ion intake was evaluated using an unstructured variance-covariance structure. If the random slope of choline ion intake was not significant $(P>0.10)$, then it was removed from the final model.

Choline as a Categorical Variable. The rationale for using choline as a categorical variable $(0$ vs. $>0$ $\mathrm{g} / \mathrm{d}$ ) was because, for some responses, the number of treatment means was limited and the amount of choline supplemented did not vary enough to evaluate linear or quadratic relationships with the response variable analyzed. The majority of experiments reporting incidence of diseases (67\%, 12 out of 18 treatment means) and hepatic concentrations of triacylglycerol and glycogen (75\%, 9 out of 12 treatment means) supplemented choline ion at $12.9 \mathrm{~g} / \mathrm{d}$. Because of the limited variability in the amount of choline ion supplemented, statistical analyses were performed with choline as a categorical variable in the models.
The initial statistical models included the following parameters: the fixed effects of choline (not supplemented vs. supplemented), $\mathrm{NE}_{\mathrm{L}} \mathrm{Pr}, \mathrm{METMPPr}$, and the random effect of experiment. For the incidence of individual diseases and number of disease cases per cow, METMPPo was not included in the statistical models as some of the diseases evaluated such as retained placenta, metritis, and milk fever occur in the first days postpartum and it is unlikely that postpartum methionine content would influence those diseases or represent a true biological effect of methionine in the diet fed postpartum. A backward elimination procedure was applied and at each step with removal of model parameters sequentially if $P>0.10$ according to the largest $P$-value. Hepatic composition was analyzed with the MIXED procedure of SAS (SAS/STAT, SAS Institute Inc.). Incidence of diseases was analyzed by logistic regression with the GLIMMIX procedure of SAS (SAS/STAT, SAS Institute Inc.) fitting a binomial distribution. Dispersion of the data was assessed by the ratio of the generalized chi-squared statistic and its degrees of freedom. Whenever the final models resulted in dispersion issues, the generalized $\chi^{2} /$ degrees of freedom either less than 0.90 or greater than 1.10, then a multiplicative dispersion parameter estimated from Pearson's statistic was added to the models. Predicted probabilities from the mixed models were computed as $\mathrm{LSM} \pm \mathrm{SEM}$ on the scale of the data with the ILINK function, concurrent with the respective adjusted odds ratios (OR) and 95\% confidence intervals.

Figures were generated with predicted responses for each treatment mean contributing data for the analysis of the specific response based on the random (best linear unbiased prediction) and fixed effects (best linear unbiased estimates) from the mixed models. Whenever the linear or quadratic effects of choline ion had statistical significance $(P \leq 0.05)$ or tended to be significant $(P \leq 0.10)$, then the best fit line was included in the figures.

Fitted values with best linear unbiased estimates when altering the supplementation of choline ion from 0 to $12.9 \mathrm{~g} / \mathrm{d}$ were computed and presented. The reason was to represent expected responses to choline ion supplementation at the median amount in the database $(12.9 \mathrm{~g} / \mathrm{d})$. For those results, the final statistical models were used and they assumed that cows were fed prepartum diets for $22 \mathrm{~d}$ and they contained the mean values for dietary $\mathrm{NE}_{\mathrm{L}}$ content pre- and postpartum (1.50 and $1.65 \mathrm{Mcal} / \mathrm{kg}$ ), METMPPr $(2.04 \%)$, METMPPo $(1.97 \%)$ observed for all treatment means included in the meta-analysis.

The classical meta-analysis methods with the METAN and METAREG procedures of STATA (Stata, 
Table 1. Descriptive statistics of the energy and protein content of diets consumed by cows prepartum and intake of protein and estimated flow of AA prepartum in parous cows ${ }^{1}$

\begin{tabular}{|c|c|c|c|c|c|c|}
\hline \multirow[b]{2}{*}{ Item } & \multicolumn{3}{|c|}{ Control $(\mathrm{n}=30)$} & \multicolumn{3}{|c|}{ Choline $^{2}(\mathrm{n}=36)$} \\
\hline & Mean \pm SD & Median & Range & Mean \pm SD & Median & Range \\
\hline $\mathrm{NE}_{\mathrm{L}}, \mathrm{Mcal} / \mathrm{kg}$ & $1.59 \pm 0.08$ & 1.60 & 1.41 to 1.72 & $1.61 \pm 0.08$ & 1.62 & 1.41 to 1.72 \\
\hline $\mathrm{CP}, \%$ & $14.3 \pm 1.6$ & 14.6 & 10.9 to 16.5 & $14.2 \pm 1.8$ & 14.6 & 10.9 to 16.5 \\
\hline $\mathrm{MP}^{3} \%$ & $9.3 \pm 1.0$ & 9.3 & 7.1 to 11.0 & $9.2 \pm 1.1$ & 9.3 & 7.1 to 11.1 \\
\hline \multicolumn{7}{|l|}{ Intake } \\
\hline $\mathrm{CP}, \mathrm{g} / \mathrm{d}$ & $1,737 \pm 334$ & 1,801 & 1,068 to 2,225 & $1,752 \pm 369$ & 1,823 & 1,046 to 2,300 \\
\hline Choline ion, g/d & 0 & 0 & - & $12.8 \pm 3.8$ & 12.9 & 5.6 to 25.2 \\
\hline \multicolumn{7}{|l|}{ Metabolizable } \\
\hline Protein, g/d & $1,124 \pm 209$ & 1,180 & 699 to 1,477 & $1,138 \pm 236$ & 1,214 & 685 to 1,558 \\
\hline Methionine, g/d & $23.0 \pm 5.0$ & 23.0 & 15.0 to 35.0 & $23.1 \pm 5.2$ & 23.5 & 14.0 to 36.0 \\
\hline Lysine, g/d & $74.3 \pm 14.1$ & 75.5 & 48.0 to 98.0 & $74.7 \pm 15.3$ & 76.0 & 46.0 to 102.0 \\
\hline EAA, g/d & $507 \pm 91$ & 520 & 326 to 655 & $512 \pm 101$ & 530 & 320 to 688 \\
\hline
\end{tabular}

${ }^{1}$ The concentration of nutrients in diets offered and the intake of nutrients were calculated using the ingredient composition of each diet with NRC (2001) and adjusted to the observed prepartum DMI of control and choline-supplemented cows.

${ }^{2}$ Intake of choline ion was calculated based on the $74.6 \%$ molar proportion of choline ion in choline chloride. The amount of rumen-escape choline and its intestinal bioavailability for the different products supplemented were not considered for statistical analysis.

${ }^{3}$ Metabolizable protein was predicted with NRC (2001) and is expressed as the percentage of the observed DMI.

${ }^{4}$ Metabolizable methionine was predicted using NRC (2001) and is expressed as the proportion of the MP.

version 14.2, StataCorp, College Station, TX) were used to generate forest plots to determine the effect size or standardized mean difference for some of the responses of interest as previously described (Lean et al., 2009). In that case, within each experiment, the effect of supplementing choline ion $(>0 \mathrm{~g} / \mathrm{d})$ was compared with no choline supplementation $(0 \mathrm{~g} / \mathrm{d})$. Supplemental Figure S2 (https://doi.org/10.3168/jds.2019-16842) depicts the funnel plots generated to investigate the publication bias as previously described (Lean et al., 2009).

\section{RESULTS}

The number of experiments reporting data for parous cows was 21 , including a total of 1,313 cows, with a range of prepartum choline ion supplemented from 5.6 to $25.2 \mathrm{~g} / \mathrm{d}$ (Supplemental Table S1, https://doi.org/10 $.3168 /$ jds.2019-16842). Nineteen of the 21 experiments supplemented RPC as top dress and supplementation occurred (mean $\pm \mathrm{SD}$ ) in the last $22.0 \pm 6.0$ of gestation, ranging from 7 to $40 \mathrm{~d}$, and continued until 57.5 $\pm 42.2 \mathrm{~d}$ postpartum, ranging from 15 to $140 \mathrm{~d}$. The duration of choline supplementation in treated cows averaged $81.8 \pm 47.4 \mathrm{~d}$, ranging from 28 to $168 \mathrm{~d}$. A detailed description of the experiments that provided data for the meta-analysis is presented in Supplemental Table S1 (https://doi.org/10.3168/jds.2019-16842). Descriptive statistics of pre- and postpartum diets are presented in Tables 1 and 2, respectively. Minor differ- ences observed in the contents of $\mathrm{NE}_{\mathrm{L}}$ and $\mathrm{MP}$ contents of diets were caused by differences in prepartum DMI. Prepartum cows consumed on average $19.3 \mathrm{Mcal} / \mathrm{d}$ of $\mathrm{NE}_{\mathrm{L}}, 1.74 \mathrm{~kg}$ of CP, $1.12 \mathrm{~kg}$ of MP, $23.0 \mathrm{~g}$ of metabolizable methionine, and $74.3 \mathrm{~g}$ of metabolizable lysine, whereas postpartum cows consumed on average 31.2 $\mathrm{Mcal} / \mathrm{d}$ of $\mathrm{NE}_{\mathrm{L}}, 3.21 \mathrm{~kg}$ of $\mathrm{CP}, 2.08 \mathrm{~kg}$ of MP, $40.8 \mathrm{~g}$ of metabolizable methionine, and $132.5 \mathrm{~g}$ of metabolizable lysine. Supplemental Table S2 (https://doi.org/ 10.3168/jds.2019-16842) presents the number of treatment means and experiments that contributed data for statistical analyses for each of the variables analyzed. It also presents the descriptive statistics of the observed responses analyzed.

\section{Effect of Supplementation of Choline Ion on Prepartum Performance in Parous Cows}

A total of 19 experiments with 62 treatment means reported DMI prepartum (Supplemental Table S2, https://doi.org/10.3168/jds.2019-16842). Increasing supplementation of choline ion during transition period linearly increased $(P<0.001)$ prepartum DMI (Table 3 and Figure 1A). Supplementing $12.9 \mathrm{~g} / \mathrm{d}$ of choline ion resulted in an increment in prepartum DMI of $0.2 \mathrm{~kg} / \mathrm{d}$ (Table 4). No interactions were observed between choline supplementation and dietary $\mathrm{NE}_{\mathrm{L}} \mathrm{Pr}$ or METMPPr or METMPPo. A total of 36 and 38 treatment means from 11 experiments were available for prepartum BW and BCS, respectively (Supplemental Table S2, https:/ 
/doi.org/10.3168/jds.2019-16842). Supplementation of choline ion had a positive linear effect $(P=0.03)$ on prepartum BW (Table 3), and an increment of $23 \mathrm{~kg}$ was observed when supplementation increased from 0 to $12.9 \mathrm{~g} / \mathrm{d}$ of choline ion (Table 4$)$. Similarly, supplementation of choline ion had a positive linear effect $(P$ $=0.04$ ) on prepartum BCS (Table 3), and an increment of 0.08 units of body condition was observed when supplementation increased from 0 to $12.9 \mathrm{~g} / \mathrm{d}$ (Table 4 ).

\section{Effect of Supplementation of Choline Ion on Postpartum Performance in Parous Cows}

Postpartum DMI was reported in 20 experiments with 64 treatment means (Supplemental Table S2, https://doi.org/10.3168/jds.2019-16842). Increasing supplementation of choline ion linearly increased $(P<$ 0.001) DMI (Table 3 and Figure 1B), and an increase of $0.5 \mathrm{~kg} / \mathrm{d}$ was observed when supplementation increased from 0 to $12.9 \mathrm{~g} / \mathrm{d}$ (Table 4). No interactions were observed for postpartum DMI between choline supplementation and $\mathrm{NE}_{\mathrm{L}} \mathrm{Pr}$ or METMPPr or METMPPo (Table 3). Postpartum BW and BCS were reported in 10 and 11 experiments, respectively (Supplemental Table S2, https://doi.org/10.3168/jds.2019-16842). Supplementation of choline ion had a positive linear effect $(P=0.001)$ on postpartum BW (Table 3$)$, and an increment of $30 \mathrm{~kg}$ of BW was observed when supplementation increased from 0 to $12.9 \mathrm{~g} / \mathrm{d}$ (Table 4).
Similarly, supplementation of choline ion had a positive linear effect $(P=0.008)$ on postpartum BCS (Table 3 ), and an increment of 0.09 units of body condition was observed when supplementation increased from 0 to $12.9 \mathrm{~g} / \mathrm{d}$ (Table 4 ).

Yields of milk, ECM, fat, and protein and efficiency of ECM yield per kilogram of DMI were reported in 21 experiments with 66 treatment means (Supplemental Table S2, https://doi.org/10.3168/jds.2019-16842). Yield of milk increased $(P<0.001)$ with supplemental choline (Table 3, Figure 1C), and an increment of 1.6 $\mathrm{kg} / \mathrm{d}$ was observed when cows were supplemented with $12.9 \mathrm{~g} / \mathrm{d}$ choline ion (Table 4). However, an interaction $(P=0.005)$ between the linear effect of choline and METMPPo was observed for milk yield (Table 3). In a diet with low METMPPo (e.g., 1.80\%), supplementing $12.9 \mathrm{~g} / \mathrm{d}$ of choline ion resulted in an increment of 2.0 $\mathrm{kg} / \mathrm{d}$ more milk; however, with high dietary METMPPo (e.g., 2.30\%), the same amount of supplemental choline ion resulted in an increment of $1.02 \mathrm{~kg} / \mathrm{d}$ (Figure 2A). Similarly, yield of ECM was affected positively $(P=$ 0.001 ) by choline ion (Table 3, Figure 1D), and an increment of $1.7 \mathrm{~kg} / \mathrm{d}$ was observed when cows were supplemented with $12.9 \mathrm{~g} / \mathrm{d}$ choline ion (Table 4). Moreover, an interaction $(P=0.004)$ between linear effect of choline and METMPPo was observed for yield of ECM (Figure 2B and Table 3). In a diet with low METMPPo (e.g., 1.80\%), supplementing $12.9 \mathrm{~g} / \mathrm{d}$ of choline ion resulted in an increment of $2.13 \mathrm{~kg} / \mathrm{d}$ more

Table 2. Descriptive statistics of the energy and protein content of diets consumed by cows postpartum and intake of protein and estimated flow of AA postpartum in parous cows

\begin{tabular}{|c|c|c|c|c|c|c|}
\hline \multirow[b]{2}{*}{ Item } & \multicolumn{3}{|c|}{ Control $(\mathrm{n}=30)$} & \multicolumn{3}{|c|}{ Choline $^{2}(\mathrm{n}=36)$} \\
\hline & Mean $\pm \mathrm{SD}$ & Median & Range & Mean \pm SD & Median & Range \\
\hline \multicolumn{7}{|l|}{ Content, DM basis } \\
\hline $\mathrm{NE}_{\mathrm{L}}, \mathrm{Mcal} / \mathrm{kg}$ & $1.65 \pm 0.04$ & 1.65 & 1.57 to 1.74 & $1.64 \pm 0.04$ & 1.64 & 1.58 to 1.76 \\
\hline $\mathrm{CP}, \%$ & $16.8 \pm 1.6$ & 17.1 & 12.0 to 18.8 & $16.7 \pm 1.9$ & 17.2 & 12.0 to 18.8 \\
\hline $\mathrm{MP}, 3 \%$ & $10.8 \pm 1.1$ & 11.3 & 7.8 to 12.3 & $10.8 \pm 1.3$ & 11.4 & 7.8 to 12.3 \\
\hline \multicolumn{7}{|l|}{ Intake } \\
\hline $\mathrm{CP}, \mathrm{g} / \mathrm{d}$ & $3,207 \pm 718$ & 3,429 & 1,775 to 4,343 & $3,291 \pm 769$ & 3,495 & 1,824 to 4,268 \\
\hline Choline ion, g/d & 0 & 0 & - & $12.8 \pm 3.8$ & 12.9 & 5.6 to 25.2 \\
\hline \multicolumn{7}{|l|}{ Metabolizable } \\
\hline Protein, g/d & $2,080 \pm 467$ & 2,132 & 1,145 to 2,749 & $2,140 \pm 490$ & 2,308 & 1,181 to 2,802 \\
\hline Methionine, $\mathrm{g} / \mathrm{d}$ & $40.8 \pm 9.3$ & 40.5 & 24.0 to 56.0 & $41.4 \pm 9.6$ & 42.0 & 24.0 to 57.0 \\
\hline Lysine, $\mathrm{g} / \mathrm{d}$ & $132.5 \pm 29.0$ & 136.0 & 75.0 to 179.0 & $134.5 \pm 29.5$ & 139.0 & 81.0 to 183.0 \\
\hline EAA, $g / d$ & $916 \pm 195$ & 940 & 532 to 1,219 & $937 \pm 202$ & 996 & 545 to 1,243 \\
\hline
\end{tabular}

${ }^{1}$ The concentration of nutrients in diets offered and the intake of nutrients were calculated using the ingredient composition of each diet with NRC (2001) and adjusted to the observed postpartum DMI of control and choline-supplemented cows.

${ }^{2}$ Intake of choline ion was calculated based on the $74.6 \%$ molar proportion of choline ion in choline chloride. The amount of rumen-escape choline and its intestinal bioavailability for the different products supplemented were not considered for statistical analysis.

${ }^{3}$ Metabolizable protein was predicted with NRC (2001) and is expressed as the percentage of the observed DMI.

${ }^{4}$ Metabolizable methionine was predicted using NRC (2001) and is expressed as the proportion of the MP. 


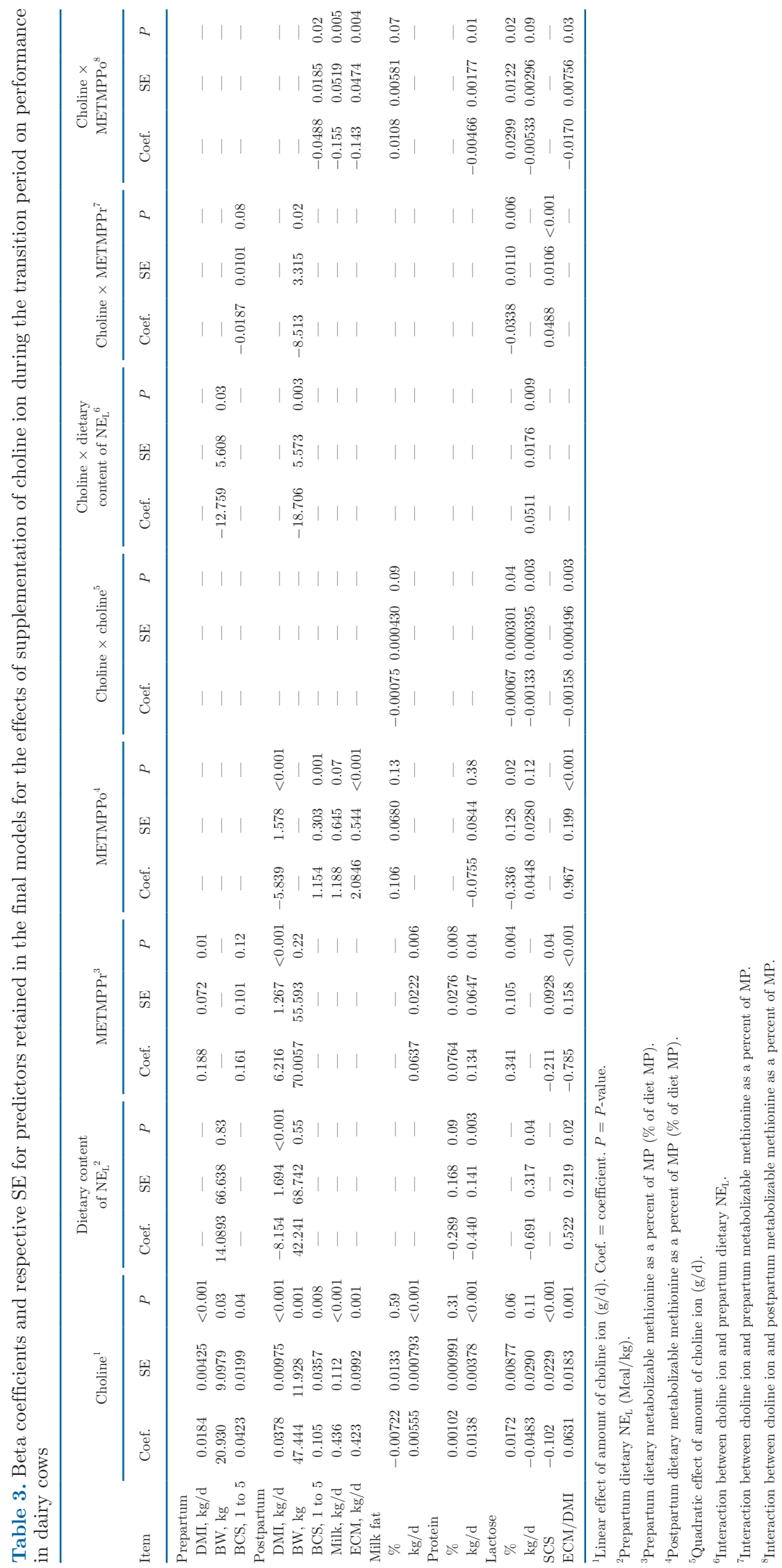



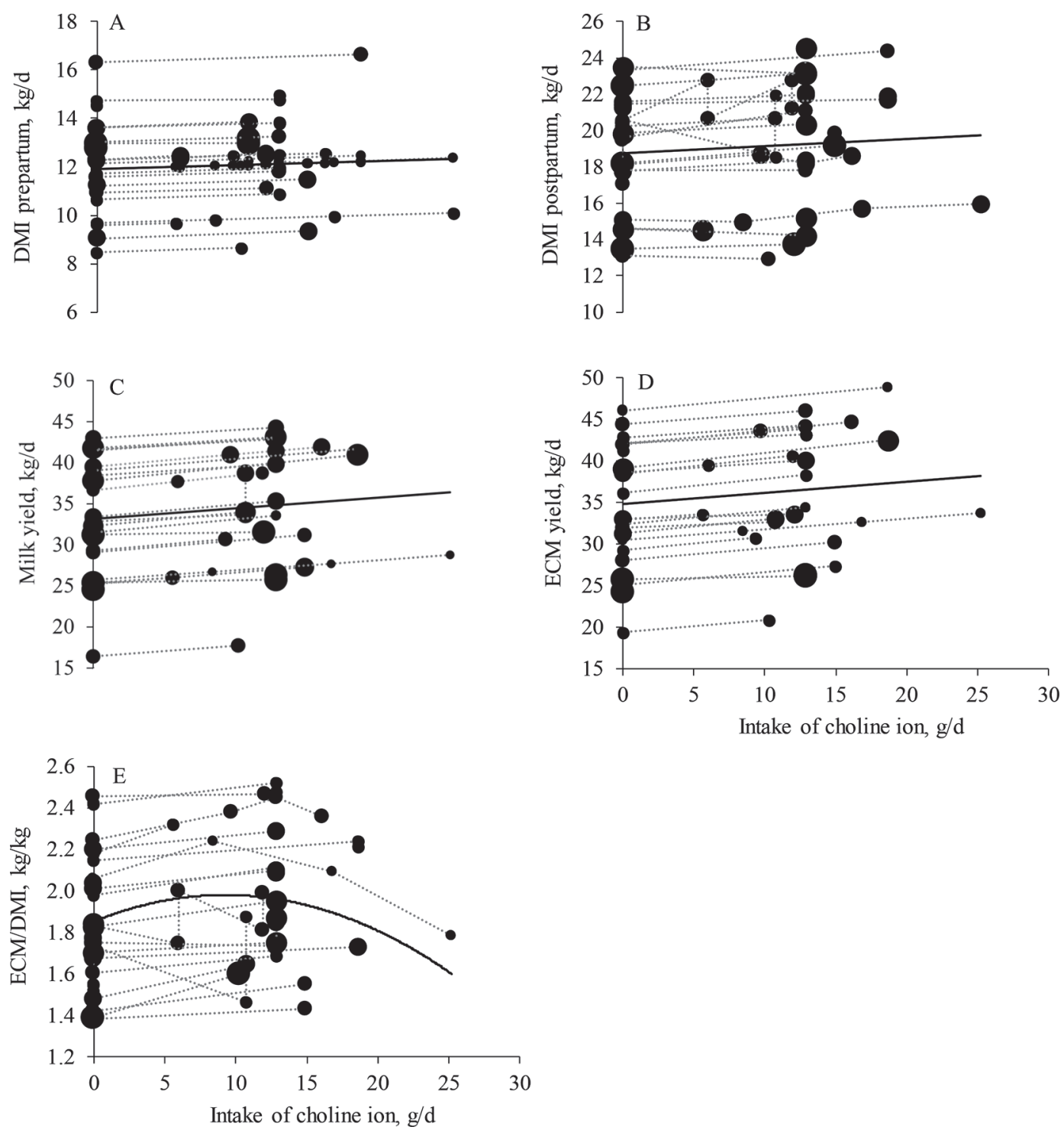

Figure 1. Adjusted values according to the fixed and random effects from the mixed models for pre- and postpartum intakes of DM, yields of milk and ECM, and feed efficiency (ECM/DMI) according to prepartum supplementation of choline ion in parous cows. Dotted connecting lines connect treatment means within the same experiment. The continuous line, presented only when statistical significance was observed, depicts the response to supply of choline ion. The size of the symbols represents the weight of treatment mean in the analysis. Prepartum DMI (A): linear effect of choline ion $(P<0.001)$. Postpartum DMI $(B)$ : linear effect of choline ion $(P<0.001)$. Milk yield $(\mathrm{C})$ : linear effect of choline ion $(P<0.001)$, and interaction between the linear effect of choline ion and postpartum metabolizable methionine as percent of MP $(P=0.005)$. Energy-corrected milk yield (D): linear effect of choline ion $(P=0.001)$, and interaction between the linear effect of choline ion and postpartum metabolizable methionine as percent of MP $(P=0.004)$. Feed efficiency $(\mathrm{E})$ : linear $(P=0.001)$ and quadratic $(P=0.003)$ effect of choline ion, and interaction between the linear effect of choline ion and postpartum metabolizable methionine as percent of $\mathrm{MP}(P=0.03)$. A: 19 experiments and 62 treatment means; B: $=20$ experiments and 64 treatment means; C: 21 experiments and 66 treatment means; D: 21 experiments and 66 treatment means; E: 20 experiments and 66 treatment means.

ECM; however, with high dietary METMPPo (e.g., $2.30 \%)$, the same amount of supplemental choline ion resulted in an increment of $1.20 \mathrm{~kg} / \mathrm{d}$ (Figure 2B). Overall, in the 36 treatment comparisons collected from the 21 experiments evaluated, the mean response to choline was $2.18 \mathrm{~kg} / \mathrm{d}$ more $(P<0.001)$ ECM than nonsupplemented cows (standardized mean difference
$=0.38 ; 95 \% \mathrm{CI}=0.21$ to 0.56; Supplemental Figure S3, https://doi.org/10.3168/jds.2019-16842), and results showed small heterogeneity. In fact, of the treatment comparisons with nonsupplemented cows, 29 of the 36 treatment comparisons available showed at least a numerical increase in ECM (Supplemental Figure S3, https://doi.org/10.3168/jds.2019-16842). 
The concentration of fat in milk showed a tendency for quadratic effect $(P=0.09)$ to choline ion (Table 3 and Figure 3A). The quadratic effect was maximized at $9.7 \mathrm{~g} / \mathrm{d}$ of choline ion, when cows produced milk with $3.97 \%$ fat. Moreover, an interaction $(P=0.07)$ between linear effect of choline and METMPPo was observed for milk fat (Table 3). Nevertheless, yield of fat increased linearly $(P<0.001)$ with supplementation of choline ion (Table 3 and Figure 3B), and an increment of 0.07 $\mathrm{kg} / \mathrm{d}$ was estimated when $12.9 \mathrm{~g} / \mathrm{d}$ of choline ion was fed to cows (Table 4). No interactions were observed for fat yield between choline supplementation and $\mathrm{NE}_{\mathrm{L}} \mathrm{Pr}$ or METMPPr or METMPPo (Table 3). No effect of supplementation with choline ion was observed for concentration of protein in milk (Table 3 and Figure 3C). However, protein yield influenced positively $(P<0.001)$ with supplementation of choline (Table 3 and Figure 3D). Feeding $12.9 \mathrm{~g} / \mathrm{d}$ of choline ion increased milk protein yield by $0.05 \mathrm{~kg} / \mathrm{d}$ (Table 4$)$. An interaction $(P$ $=0.01$ ) between linear effect of choline and METMPPo was observed for yield of protein (Table 3). In a diet with low METMPPo (e.g., 1.80\%), supplementing 12.9 $\mathrm{g} / \mathrm{d}$ of choline ion resulted in an increment of $0.07 \mathrm{~kg} / \mathrm{d}$ more protein; however, with high dietary METMPPo (e.g., 2.30\%), the same amount of supplemental cho- line ion resulted in an increment of $0.04 \mathrm{~kg} / \mathrm{d}$ (Figure $2 \mathrm{C})$. The concentration of lactose in milk responded quadratically $(P=0.04)$ to choline ion (Table 3$)$. The quadratic effect was maximized at $8.0 \mathrm{~g} / \mathrm{d}$ of choline ion, when cows produced milk with $4.80 \%$ lactose. Moreover, interactions $(P<0.05)$ between linear effect of choline and METMPPr, and METMPPo were observed for lactose concentration (Table 3). Similarly, yield of lactose increased quadratically $(P=0.003)$ and interactions between linear effect of choline and dietary $\mathrm{NE}_{\mathrm{L}} \operatorname{Pr}(P=0.009)$ and METMPPo $(P=0.09)$ were observed for yield of lactose (Table 3 ), whereas SCS decreased linearly $(P<0.001)$ with supplementation of choline (Table 3$)$. A quadratic effect $(P=0.003)$ of supplementation of choline ion was observed for efficiency of ECM yield per $\mathrm{kg}$ of DMI (Table 3 and Figure $1 \mathrm{E}$ ). The quadratic response was maximized at $9.2 \mathrm{~g} / \mathrm{d}$ of choline ion, when feed efficiency was 1.98 $\mathrm{kg}$ of ECM per $\mathrm{kg}$ of DMI. Feeding choline at $12.9 \mathrm{~g} / \mathrm{d}$ increased efficiency approximately $12.0 \%$ (Table 4). Moreover, an interaction $(P=0.03)$ between linear effect of choline and METMPPo was observed for feed efficiency (Table 3). In a diet with low METMPPo (e.g., $1.80 \%$ ), supplementing $12.9 \mathrm{~g} / \mathrm{d}$ of choline ion resulted in an increment of 0.16 in feed efficiency; however, with

Table 4. Least squares means and respective SEM for responses in parous cows when supplemented with 0 or $12.9 \mathrm{~g} / \mathrm{d}$ of choline ion during the transition period ${ }^{1}$

\begin{tabular}{|c|c|c|c|c|}
\hline \multirow[b]{2}{*}{ Item } & \multicolumn{2}{|c|}{ Choline ion, $\mathrm{g} / \mathrm{d}$} & \multicolumn{2}{|c|}{$P$-value ${ }^{2}$} \\
\hline & 0 & 12.9 & Choline & Choline $\times$ choline \\
\hline \multicolumn{5}{|l|}{ Prepartum } \\
\hline DMI, kg/d & $11.9 \pm 0.5$ & $12.1 \pm 0.5$ & $<0.001$ & - \\
\hline $\mathrm{BW}, \mathrm{kg} / \mathrm{d}$ & $676 \pm 27$ & $699 \pm 27$ & 0.03 & - \\
\hline BCS, 1 to 5 & $3.42 \pm 0.09$ & $3.50 \pm 0.09$ & 0.04 & - \\
\hline \multicolumn{5}{|l|}{ Postpartum } \\
\hline DMI, kg/d & $19.2 \pm 0.7$ & $19.7 \pm 0.7$ & $<0.001$ & - \\
\hline $\mathrm{BW}, \mathrm{kg} / \mathrm{d}$ & $605 \pm 24$ & $635 \pm 24$ & 0.001 & - \\
\hline BCS 1 to 5 & $2.98 \pm 0.06$ & $3.07 \pm 0.06$ & 0.008 & - \\
\hline Milk, $\mathrm{kg} / \mathrm{d}$ & $33.2 \pm 1.6$ & $34.8 \pm 1.6$ & $<0.001$ & - \\
\hline $\mathrm{ECM}, \mathrm{kg} / \mathrm{d}$ & $34.8 \pm 1.6$ & $36.5 \pm 1.6$ & 0.001 & - \\
\hline \multicolumn{5}{|l|}{ Milk fat } \\
\hline$\%$ & $3.90 \pm 0.12$ & $3.96 \pm 0.12$ & 0.59 & 0.09 \\
\hline $\mathrm{kg} / \mathrm{d}$ & $1.29 \pm 0.07$ & $1.36 \pm 0.07$ & $<0.001$ & - \\
\hline \multicolumn{5}{|l|}{ Protein } \\
\hline$\%$ & $3.12 \pm 0.03$ & $3.13 \pm 0.03$ & 0.31 & - \\
\hline $\mathrm{kg} / \mathrm{d}$ & $1.06 \pm 0.05$ & $1.11 \pm 0.05$ & $<0.001$ & - \\
\hline \multicolumn{5}{|l|}{ Lactose } \\
\hline$\%$ & $4.77 \pm 0.02$ & $4.78 \pm 0.02$ & 0.06 & 0.04 \\
\hline $\mathrm{kg} / \mathrm{d}$ & $1.65 \pm 0.12$ & $1.66 \pm 0.12$ & 0.11 & 0.003 \\
\hline SCS & $2.81 \pm 0.37$ & $2.75 \pm 0.37$ & $<0.001$ & - \\
\hline ECM/DMI & $1.84 \pm 0.07$ & $1.96 \pm 0.07$ & 0.001 & 0.003 \\
\hline
\end{tabular}

${ }^{1}$ Results from the final multivariable models when parous cows were fed diets supplemented with either 0 or $12.9 \mathrm{~g} / \mathrm{d}$ of choline ion during the transition period and pre- and postpartum diets contained, respectively, 1.50 and $1.65 \mathrm{Mcal}$ of $\mathrm{NE}_{\mathrm{L}} / \mathrm{kg}$ and $2.04 \%$ and $1.97 \%$ of the MP as metabolizable methionine.

${ }^{2}$ Choline $=$ linear effect of choline ion $(\mathrm{g} / \mathrm{d})$; choline $\times$ choline $=$ quadratic effect of choline ion . Dashes indicate that the final multivariable model did not include the quadratic effect of choline because $P>0.10$. 
high dietary METMPPo (2.30\%), the same amount of supplemental choline ion resulted in an increment in $\mathrm{kg}$ of ECM per kg of DMI of 0.05 (Figure 2D).

\section{Concentrations of Metabolites in Blood of Parous Cows}

The patterns of concentrations of metabolites in blood pre- and postpartum in response to choline ion is presented in Figure 4. Increasing supplementation of choline ion during transition linearly increased pre$(P=0.03)$ and postpartum concentrations of blood glucose $(P=0.04)$ in dairy cows (Table 5 and Figure $4 \mathrm{~A}$ and $4 \mathrm{~B}$ ). Feeding $12.9 \mathrm{~g} / \mathrm{d}$ of choline ion increased concentrations of glucose pre- and postpartum period by 0.05 and $0.04 \mathrm{mM}$, respectively (Table 6 ). Concentrations of BHB did not differ during prepartum (Table 5; Figure 4C); however, supplementation with choline ion had a tendency $(P=0.09)$ for quadratic effect on BHB during postpartum period (Table 5 and Figure 4D). The quadratic effect was maximized at $8.1 \mathrm{~g} / \mathrm{d}$ of choline ion, which resulted in a blood concentra- tion of $0.82 \mathrm{~m} M$ of BHB. A small linear increase $(P$ $=0.02)$ in prepartum blood fatty acids was observed with supplementing choline ion (Table 5 and Figure $4 \mathrm{E})$. However, for the postpartum period, supplementation with choline resulted in a reduction $(P=0.03)$ on concentration of fatty acids in blood (Table 5). Feeding $12.9 \mathrm{~g} / \mathrm{d}$ of choline ion decreased concentrations of fatty acids during the postpartum period by $0.08 \mathrm{~m} M$ (Table $6)$. An interaction $(P<0.05)$ between linear effect of choline and dietary $\mathrm{NE}_{\mathrm{L}} \mathrm{Pr}$ was observed for pre- and postpartum fatty acids (Table 5).

\section{Incidence of Diseases and Concentrations of Hepatic Triacylglycerol and Glycogen}

Reporting of individual diseases varied across experiments (Supplemental Table S2, https://doi.org/ 10.3168/jds.2019-16842). Supplementing choline ion tended $(P=0.06)$ to reduce the risk of retained placenta in parous cows (adjusted OR $=0.69 ; 95 \%$ CI $=0.46$ to 1.02) and that of mastitis (adjusted $\mathrm{OR}=$ $0.76 ; 95 \%$ CI $=0.55$ to 1.06$)$; however, no effect of
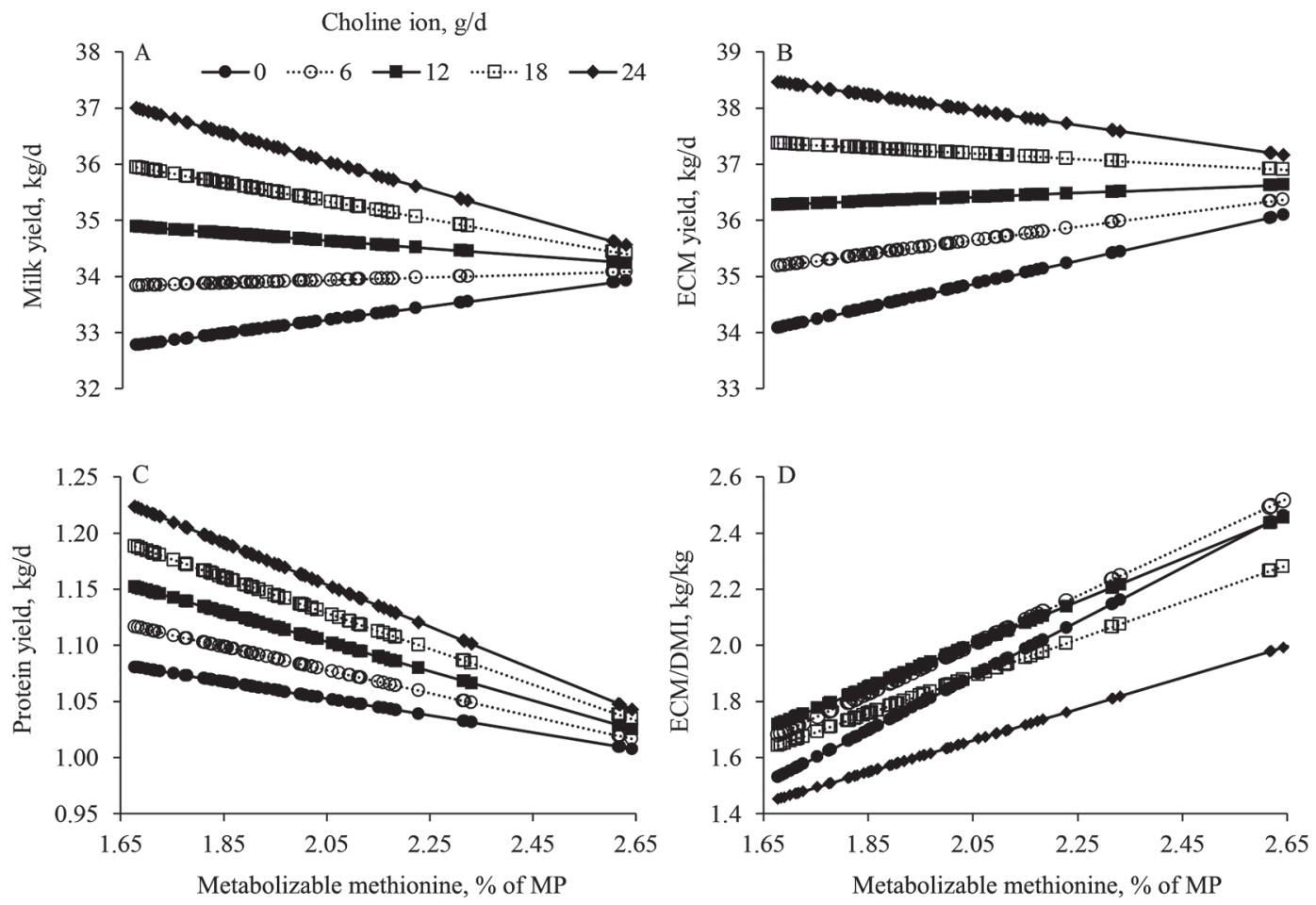

Figure 2. Adjusted values according to the fixed and random effects from the mixed models for yields of milk, ECM, protein, and feed efficiency according to supplementation of choline ion and postpartum supply of metabolizable methionine as percent of MP. Milk yield (A): linear effect of choline ion $(P<0.001)$, and interaction between the linear effect of choline ion and postpartum metabolizable methionine as percent of MP $(P=0.005)$. Energy-corrected milk yield $(B)$ : linear effect of choline ion $(P<0.001)$, and interaction between the linear effect of choline ion and postpartum metabolizable methionine as percent of MP $(P=0.004)$. Protein yield $(\mathrm{C})$ : linear effect of choline ion $(P<0.001)$, and interaction between the linear effect of choline ion and postpartum metabolizable methionine as percent of MP $(P=0.01)$. Energy-corrected milk yield over DMI $(\mathrm{D})$ : linear $(P=0.001)$ and quadratic $(P=0.003)$ effect of choline ion, and interaction between the linear effect of choline ion and postpartum metabolizable methionine as percent of MP $(P=0.03)$. 
supplementation was observed for incidence of metritis, milk fever, displaced abomasum, and ketosis (Table 7). The number of disease cases per cow did not differ $(P$ $=0.23)$ because of supplementation with choline ion.

Concentrations of hepatic triacylglycerol and glycogen postpartum were reported in 8 experiments with 22 treatment means and 4 experiments and 10 treatment means, respectively (Supplemental Table S2, https:// doi.org/10.3168/jds.2019-16842). Supplementing choline did not affect hepatic triacylglycerol postpartum; however, choline decreased $(P=0.009)$ the concentrations of glycogen in the liver of postpartum cows (Table 7).

\section{DISCUSSION}

Numerous reports from randomized controlled experiments provide strong evidence of the role of choline in a rumen-protected form supplemented during the transition period on productive performance in dairy cows (Baldi and Pinotti, 2006; Sun et al., 2016; Zenobi et al., 2018a). In fact, strong evidence indicates that, like in monogastrics, choline is an essential nutrient for ruminants with roles on lipid intermediary metabolism (Cooke et al., 2007; Zenobi et al., 2018b), either because of potential roles on attenuating lipolysis (Cooke et al., 2007), improving export of hepatic fatty acids (Piepenbrink and Overton, 2003), enhancing uptake of fatty acids (Zenobi et al., 2018b), or because of its role in attenuating inflammation (Sun et al., 2016), all of which would likely favor lactation performance and postpartum health. The current study demonstrated that supplementation of choline ion in a rumen-protected form increased pre- and postpartum DMI and improved yields of milk, ECM, fat, and protein in parous dairy cows. Although overwhelming evidence was observed for the benefits of choline on lactation performance, less evidence was detected for its role in improving health of dairy cows. Feeding RPC tended to reduce retained placenta and mastitis; however, no effect was observed for other diseases evaluated or for the concentration of hepatic triacylglycerol postpartum. An interesting
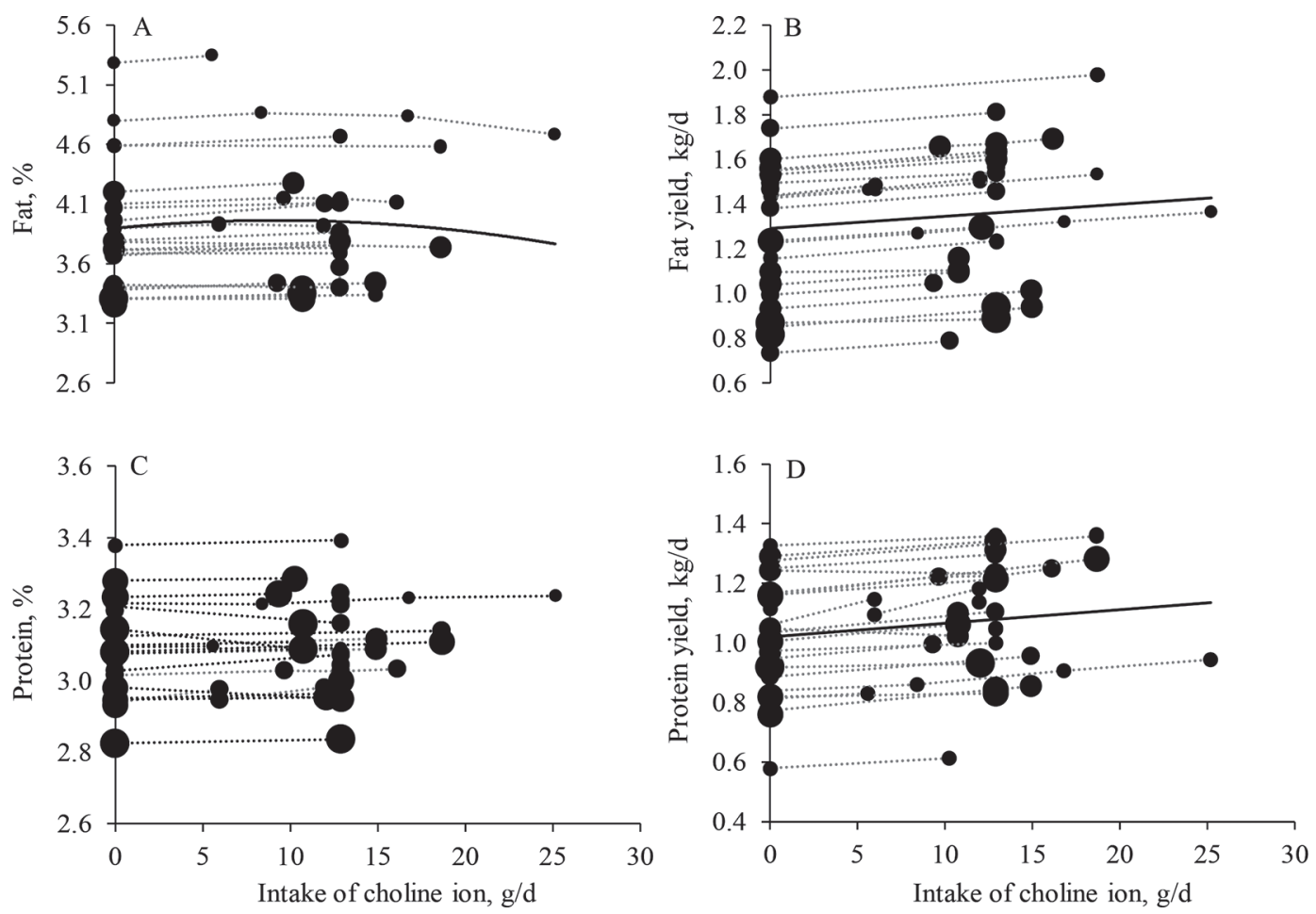

Figure 3. Adjusted values according to the fixed and random effects from the mixed models for concentrations and yields of fat and protein in milk according to supplementation of choline ion in parous cows. Dotted connecting lines connect treatment means within the same experiment. The continuous line, presented only when statistical significance was observed, depicts the response to supply of choline ion. The size of the symbols represents the weight of treatment mean in the analysis. Fat percent $(\mathrm{A})$ : linear $(P=0.59)$ and quadratic $(P=0.09)$ effect of choline ion, and interaction between the linear effect of choline ion and postpartum metabolizable methionine as percent of MP $(P=0.07)$. Fat yield (B): linear effect of choline ion $(P<0.001)$. Protein percent $(\mathrm{C})$ : linear effect of choline ion $(P=0.31)$. Protein yield $(\mathrm{D})$ : linear effect of choline ion $(P<0.001)$, and interaction between the linear effect of choline ion and postpartum metabolizable methionine as percent of MP $(P$ $=0.01)$. A: 21 experiments and 66 treatment means; $\mathrm{B}:=21$ experiments and 66 treatment means; C: 21 experiments and 66 treatment means; D: 21 experiments and 66 treatment means. 
aspect was that the benefits of supplemental choline increased as postpartum diets supplied less metabolizable methionine as a proportion of the MP.

Yields of milk and ECM in parous cows increased linearly with the amount of choline ion supplemented during the transition period. Supplemental Figure S3 (https://doi.org/10.3168/jds.2019-16842) shows consistency in ECM yield response to supplemental choline and the small heterogeneity detected might, in part, be related to the linear effect observed for choline ion on yield of ECM or the fact that magnitude of response to choline depended on the concentration of methionine in the MP of the postpartum diets. Choline has numerous roles in mammalian metabolism; in particular, it participates in the synthesis of phospholipids that are critical for cell membrane synthesis and absorp-
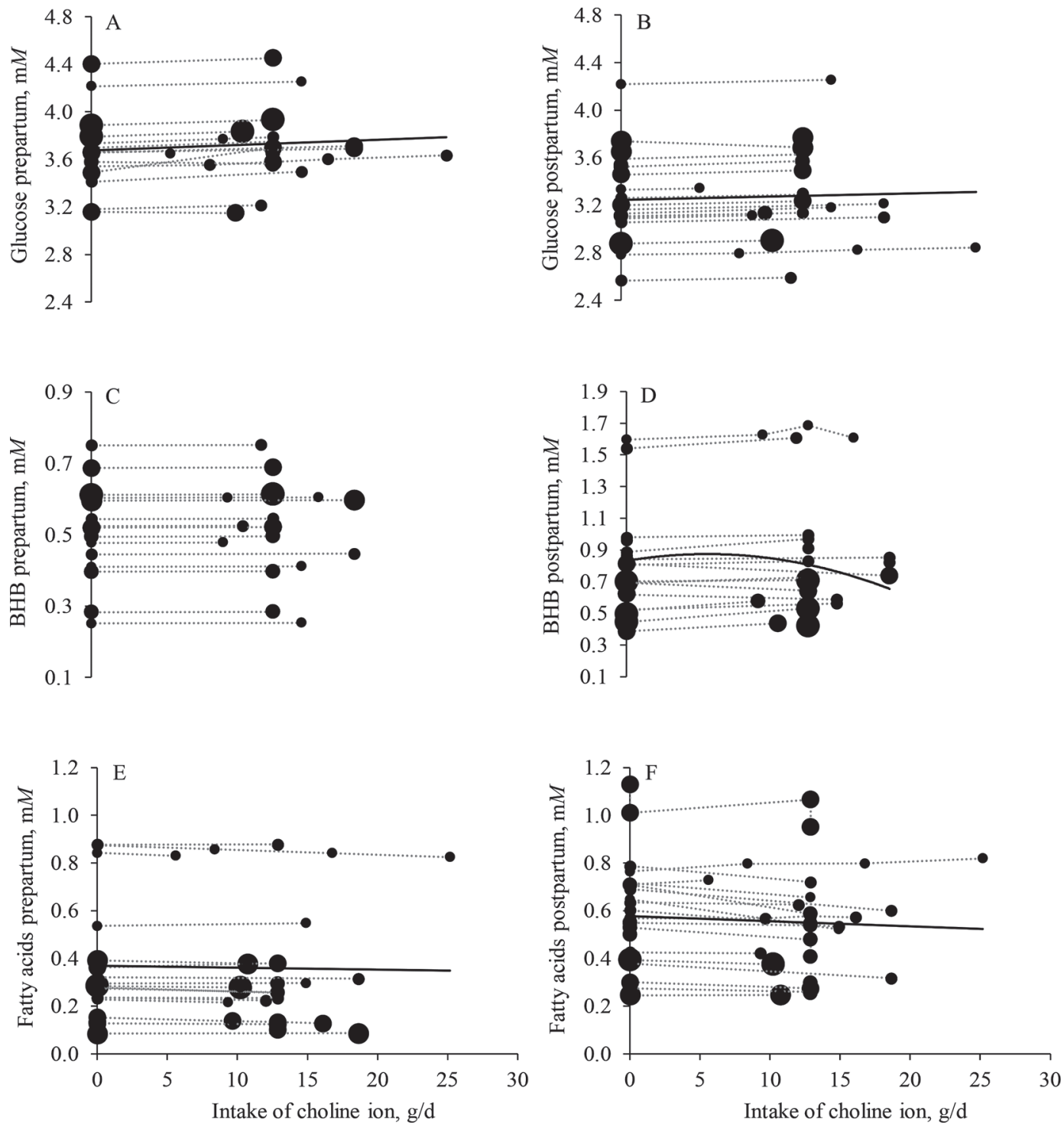

Figure 4. Adjusted values according to the fixed and random effects from the mixed models for plasma concentrations of metabolites preand postpartum according to supplementation of choline ion in parous cows. Dotted connecting lines connect treatment means within the same experiment. Continuous line, presented only when statistical significance was observed, depicts the response to supply of choline ion. The size of the symbols represents the weight of treatment mean in the analysis. Glucose prepartum (A): linear effect of choline ion $(P=0.03)$. Glucose postpartum $(\mathrm{B})$ : linear effect of choline ion $(P=0.04)$. $\beta$-Hydroxybutyrate prepartum $(\mathrm{C})$ : linear effect of choline ion $(P=0.69)$. $\beta$-Hydroxybutyrate postpartum $(\mathrm{D})$ : linear $(P=0.05)$ and quadratic $(P=0.09)$ effect of choline ion. Fatty acids prepartum $(\mathrm{E})$ : linear effect of choline ion $(P=$ $0.02)$, and interaction between the linear effect of choline ion and prepartum dietary $\mathrm{NE}_{\mathrm{L}}(P=0.01)$. Fatty acids postpartum $(\mathrm{F})$ : linear effect of choline ion $(P=0.03)$, and interaction between the linear effect of choline ion and prepartum dietary $\mathrm{NE}_{\mathrm{L}}(P=0.04)$. A: 16 experiments and 44 treatment means; B: $=17$ experiments and 46 treatment means; C: 18 experiments and 52 treatment means; D: 19 experiments and 54 treatment means; E: 15 experiments and 44 treatment means; F: $=16$ experiments and 46 treatment means. 


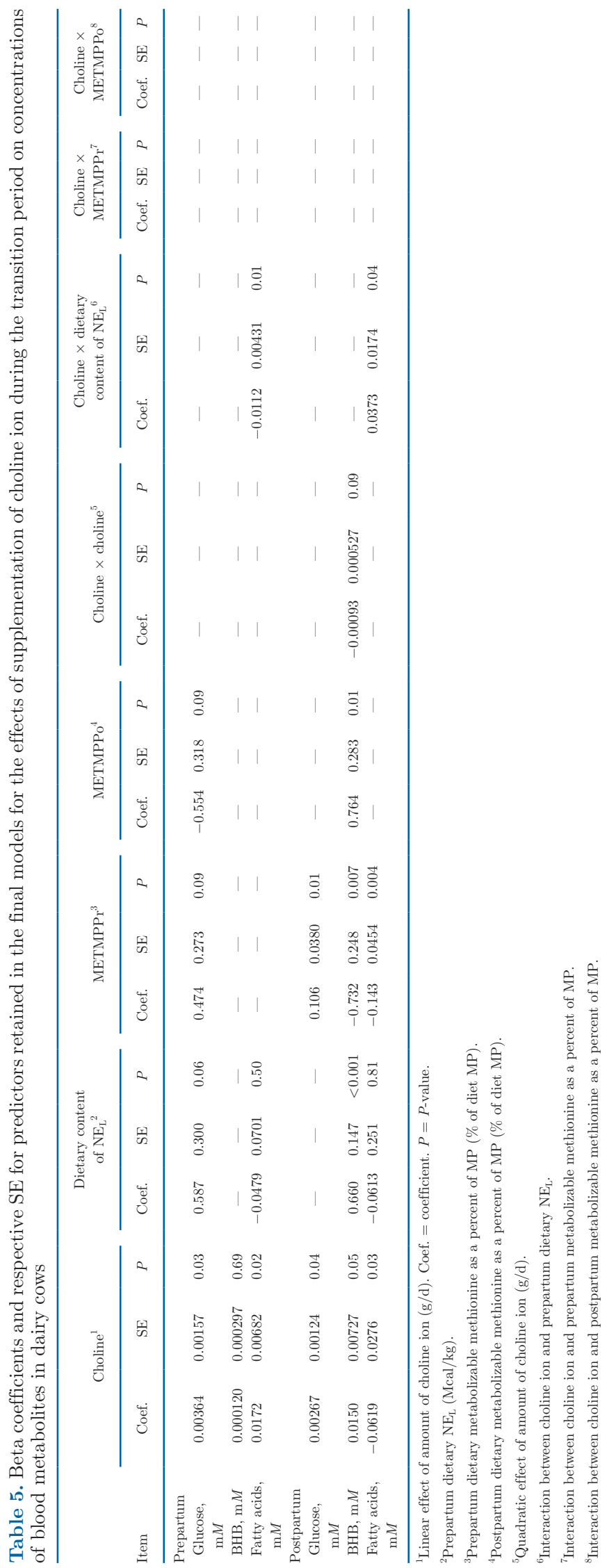

tion of fatty acids and fat-soluble molecules. There is some indication that abrupt changes in DMI can alter intestinal gut barrier in dairy cattle (Kvidera et al., 2017), and choline might play a role in maintaining tissue integrity because of its role in synthesis of phospholipids needed to maintain an intact barrier of the gastrointestinal tract (Braun et al., 2009). Improving gut barrier might benefit transition cows because of improved nutrient absorption and prevention of entry of microbial antigens that results in inflammation and immune responses. Dry cows subjected to feed restriction had increased plasma triacylglycerol after a fat challenge when supplemented with increasing amounts of choline ion (Zenobi et al., 2018b), which can be related to the role of phospholipids on tissue integrity.

Supplementing choline as RPC to dairy cows increased the net portal drained viscera flux of choline metabolites, although the relative bioavailability of choline in RPC was only $13 \%$ of that observed after abomasally infused choline as choline chloride (de Veth et al., 2016). Nevertheless, supplementing choline ion as $\mathrm{RPC}$ increases plasma choline metabolites (Zenobi et al., 2018b), which should supply additional choline and phosphatidylcholine to the mammary gland. In fact, supplementing choline as RPC increases the concentration of choline in milk of dairy cows (Elek et al., 2008). Secretion of milk lipids requires choline and it has been shown that ruminant mammary tissue uses cytidine5-diphosphocholine for synthesis of phosphatidylcholine, lysophosphatidylcholine, and sphingomyelin secreted in milk (Kinsella, 1969). Because supplementing RPC to lactating dairy cows usually increases yields of milk and milk fat (Erdman and Sharma, 1991; Davidson et al., 2008; Mohsen et al., 2011), it is possible that the effects of choline might be related to the supply or transport (or both) of lipids to the mammary gland. In lactating goats, radiolabeled choline contributed $19 \%$ of the total phospholipid pool (Emmanuel and Kennelly, 1984), thereby emphasizing the importance of choline to ruminant phospholipid synthesis. Increasing the supply of choline by postruminal infusion or feeding of RPC increased the concentration of choline in milk of mid-lactation cows (Deuchler et al., 1998), suggesting that increasing the supply of choline increases its use by the bovine mammary gland. In fact, a positive relationship exists between plasma and milk phosphatidylcholine, and concentrations usually increase with week in lactation (Artegoitia et al., 2014), presumably because of increased supply or reduced utilization with less milk yield. It is possible that increasing the supply of choline by feeding RPC during the transition period would provide phosphatidylcholine needed for mammary cell turnover. Recent work by Bollatti et al. (2018) and Zenobi et al. (2018a) showed that 
supplementing choline from $3 \mathrm{wk}$ prepartum to $3 \mathrm{wk}$ postpartum increased peak milk yield and the benefits on yields of milk or ECM carried over for at least $105 \mathrm{~d}$ postpartum. This carry-over effect might be related to potential benefits to health, intermediary metabolism, or perhaps effects of choline on the mammary gland. It has been reported that choline kinase, one of the rate-limiting enzymes in phosphatidylcholine synthesis, is required for mammary cell proliferation (Ramírez de Molina et al., 2004). It is possible that supplying additional choline, when mammary cell turnover is high, might benefit mammary epithelial cell proliferation and influence subsequent milk yield. Furthermore, because supplementing choline increased postpartum DMI, it is expected that the increased supply of nutrients should support additional milk yield. In fact, the observed increased in DMI of $0.5 \mathrm{~kg} / \mathrm{d}$ would likely support at least $1.1 \mathrm{~kg}$ of ECM, or $50 \%$ of the observed response with supplemental choline ion in the present study.

Increased yields of milk components from feeding RPC have generally been the result of increased milk yield with some effects on concentration of milk fat. Erdman et al. (1984) reported that dietary supplementation with unprotected choline chloride had positive effects on milk fat percentage and the authors suggested that choline might play a lipotropic role in stimulating milk fat synthesis. These results are interesting because most dietary choline is degraded by rumen microbes and dietary choline does not seem to affect rumen $\mathrm{pH}$ or concentrations of short-chain fatty acids in the rumen (Erdman et al., 1984). Abomasal infusion of $30 \mathrm{~g}$ of choline in dairy cows increased milk yield and fat content in milk (Sharma and Erdman, 1989b). Like in cows, feeding RPC to dairy goats increased the concentration and yield of fat in milk (Pinotti et al., 2008). It is often suggested that increases in milk fat content or yield are the result of enhanced lipid transport with supplemental choline, either from absorption of fatty acids from dietary origin as chylomicrons or from mobilized adipose tissue that might eventually be exported from the liver as very low density lipoproteins (Baldi and Pinotti, 2006). Piepenbrink and Overton (2003) suggested that dairy cows fed RPC might have increased hepatic lipoprotein secretion based on the fate of carbon-labeled palmitate metabolism in liver slices collected from cows fed different amounts of choline ion. Recent work by Chandler and White (2017) demonstrated that incubation of primary neonatal bovine hepatocytes in presence of increasing amounts of choline as choline chloride linearly increased the secretion of very low density lipoprotein and decreased the accumulation of reactive oxygen species in the culture medium. Theoretically, improving choline supply likely contributes to fatty acid transport in blood and more triglyceride-rich lipoproteins might be available to the mammary gland. Furthermore, Zenobi et al. (2018b) recently proposed that supplementation of choline ion may increase the absorptive capacity of small intestine that help deliver nutrients, in particular fatty acids, to dairy cows. Indeed, supplementing choline to dairy cows increased total-tract apparent digestibility of fat (Mohsen et al., 2011). In the current study, supplementation of choline increased yields of protein and lactose because of increased milk production, with no effect on concentrations in milk.

Except for $\mathrm{Xu}$ et al. (2006), all other experiments supplemented choline to transition cows during at least the last $14 \mathrm{~d}$ of gestation and continued for at least the first 15 DIM. Indeed, the duration of supplementing RPC during the transition period averaged $( \pm \mathrm{SD})$ $81.8 \pm 47.7 \mathrm{~d}$, with a range of 28 to $168 \mathrm{~d}$. Bollatti et al. (2018) recently showed that when cows are supple-

Table 6. Least squares means and respective SEM for concentrations of blood analytes in parous cows when supplemented with 0 or $12.9 \mathrm{~g} / \mathrm{d}$ of choline ion during the transition period ${ }^{1}$

\begin{tabular}{|c|c|c|c|}
\hline \multirow[b]{2}{*}{ Item } & \multicolumn{2}{|c|}{ Choline ion, $\mathrm{g} / \mathrm{d}$} & \multirow[b]{2}{*}{$P$-value ${ }^{2}$} \\
\hline & 0 & 12.9 & \\
\hline \multicolumn{4}{|l|}{ Prepartum $^{3}$} \\
\hline Glucose, $\mathrm{m} M$ & $3.62 \pm 0.09$ & $3.67 \pm 0.09$ & 0.03 \\
\hline $\mathrm{BHB}, \mathrm{m} M$ & $0.51 \pm 0.04$ & $0.51 \pm 0.04$ & 0.69 \\
\hline Fatty acids, $\mathrm{m} M$ & $0.37 \pm 0.06$ & $0.38 \pm 0.05$ & 0.02 \\
\hline \multicolumn{4}{|l|}{ Postpartum } \\
\hline Glucose, $\mathrm{m} M$ & $3.24 \pm 0.10$ & $3.28 \pm 0.10$ & 0.04 \\
\hline $\mathrm{BHB}, \mathrm{m} M$ & $0.80 \pm 0.08$ & $0.76 \pm 0.09$ & 0.05 \\
\hline Fatty acids, $\mathrm{m} M$ & $0.59 \pm 0.06$ & $0.51 \pm 0.06$ & 0.03 \\
\hline
\end{tabular}

${ }^{1}$ Results from the final multivariable models when parous cows were fed diets supplemented with either 0 or $12.9 \mathrm{~g} / \mathrm{d}$ of choline ion during the transition period and pre- and postpartum diets contained, respectively, 1.50 and $1.65 \mathrm{Mcal}$ of $\mathrm{NE}_{\mathrm{L}} / \mathrm{kg}$ and $2.04 \%$ and $1.97 \%$ of the $\mathrm{MP}$ as metabolizable methionine.

${ }^{2}$ Refers to the linear effect of choline ion (g/d) except for concentration of BHB postpartum, in which the $P$-value refers to the quadratic effect observed. 


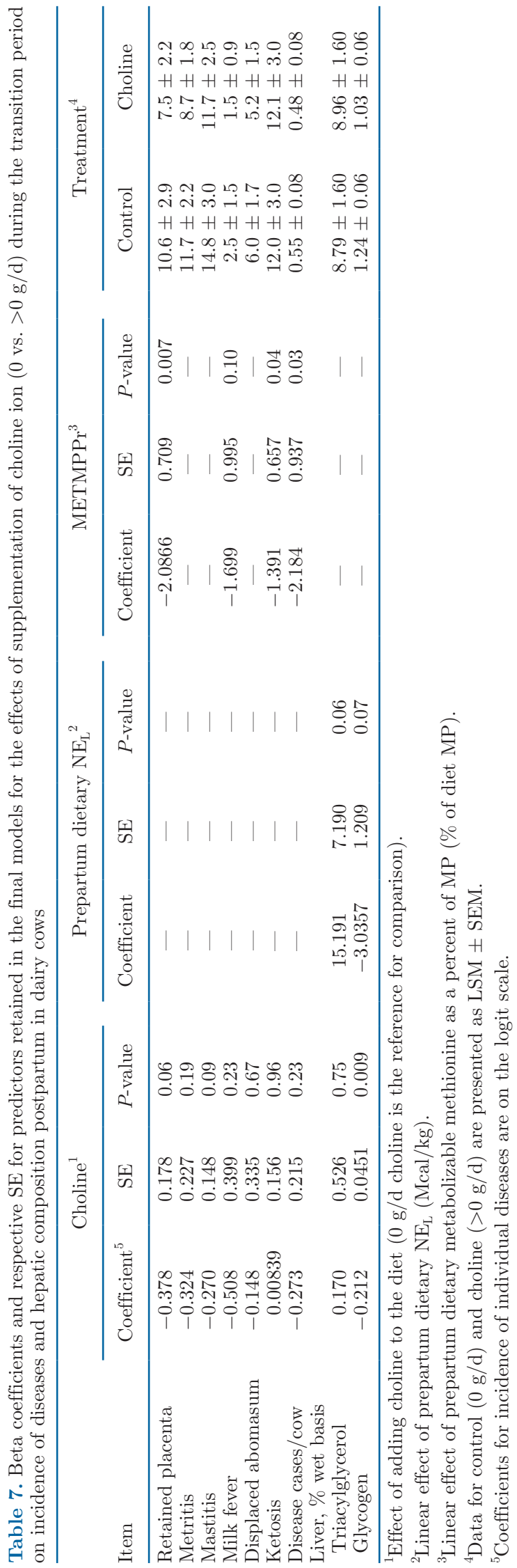

mented with $12.9 \mathrm{~g} / \mathrm{d}$ of choline ion as RPC, which is the median value observed in the databased for the present meta-analysis, there were no benefits of extending supplementation past 21 DIM. Collectively, these results suggest that supplementing RPC during the last weeks of gestation and the first weeks of lactation benefit productive performance irrespective of the duration of supplementation. Nevertheless, it is important to indicate that responses to choline were linear up to $25.2 \mathrm{~g} / \mathrm{d}$, the upper limit of the database investigated. Others have shown that supplementing choline during mid-lactation in doses of at least $27 \mathrm{~g} / \mathrm{d}$ benefit performance of dairy cows (Erdman and Sharma, 1991; Davidson et al., 2008). Therefore, it is possible that the inability to detect a benefit for the duration of supplementation was related to the dose and, perhaps, as lactation progresses and production increases, dairy cows might respond to choline if supplemented in larger quantities than those used in the present study.

A core objective of this meta-analysis was to determine if supplementation of choline to diets fed to transition cows affects the risk of diseases. We observed that supplementation of choline tended to reduce the incidence of retained placenta and that of mastitis; however, it had no effect on other periparturient disorders. Furthermore, supplementing choline did not affect hepatic triacylglycerol concentration postpartum, and reduced the concentration of hepatic glycogen. The lack of benefit from feeding choline on hepatic triacylglycerol might be related to the positive effects on production of ECM and the increased feed efficiency of $0.13 \mathrm{~kg}$ more ECM per $\mathrm{kg}$ of DMI observed in the present study. It is possible that the well-characterized effects of choline in reducing hepatic triacylglycerol in dry cow models (Cooke et al., 2007; Zenobi et al., 2018b) might have been overshadowed by the increased nutrient demands for milk synthesis that was stimulated by choline supplementation. Although we do not have data on incidence of fatty liver for this study, the similar content of hepatic triacylglycerol suggests that supplementation with choline did not influence the incidence of fatty liver. Perhaps, the lack of effect of choline on hepatic triacylglycerol content explains the inability of choline supplementation to reduce the risk of displaced abomasum and ketosis. Nevertheless, it is interesting that choline tended to reduce the risk of retained placenta and mastitis. A decrease in the number of disease events per cow was observed, likely because of the reduced incidence in retained placenta and mastitis. It is well established that diseases impair lactation performance and a reduction in the number of clinical events per cow is likely to contribute to the improved lactation performance observed in the present study. 
Lima et al. (2012) observed that supplementing 12.9 $\mathrm{g}$ of choline ion reduced the incidence of retained placenta in nulliparous cows and that of mastitis in all cows. The exact mechanism by which choline might reduce these 2 diseases is unclear; however, supplementation of choline has been shown to have anti-inflammatory effects by reducing plasma concentrations of pro-inflammatory cytokines (Sun et al., 2016), but also improved measures of immune function in transition cows (Vailati-Riboni et al., 2017). It is possible that supplementation with choline attenuated the dysregulated pro-inflammatory responses typically associated with the initiation of lactation in dairy cows. Therefore, supplementation of choline might benefit and provide a more coordinated innate immune response against the fetal placental tissues after the calving process. Also, improved innate immune defenses might reduce the risk of mastitis in early lactation. Furthermore, Zenobi et al. (2018a) observed that cows supplemented with choline had greater concentration of total $\mathrm{Ca}$ in plasma in the first 7 DIM, and both Bollatti et al. (2018) and Zenobi et al. (2018a) observed a reduced risk of subclinical hypocalcemia with choline supplementation. Subclinical hypocalcemia suppresses innate immune response (Martinez et al., 2014), and improving Ca homeostasis around parturition has been shown to reduce the risk of retained placenta and metritis in dairy cows (Santos et al., 2019).

In the current study, interactions were observed between choline and postpartum intake of metabolizable methionine as percentage of MP for yields of milk, ECM, and protein suggesting that the magnitude of benefit to supplemental RPC not only depends on the amount of choline ion supplemented, but also the concentration of methionine in the MP supplied in the diet postpartum. A common suggestion is that cows respond to choline when diets are not balanced for methionine because of the interplay of the 2 molecules in the 1-C metabolism. Nevertheless, responses to choline were also observed when metabolizable methionine was a large proportion of MP, although the magnitude of the effect was less. Even when metabolizable methionine represented $2.30 \%$ of MP, the median dose of choline ion fed in all experiments, $12.9 \mathrm{~g} / \mathrm{d}$ resulted in an increase in milk yield of $1.20 \mathrm{~kg} / \mathrm{d}$. Nevertheless, it is important to note that at low inclusions of choline ion and diets with very high methionine, the responses in yields of milk and ECM seemed to be negligible. In general, only a very small amount of the choline or total phospholipid pools are derived from methionine, 6 and 4\%, respectively (Emmanuel and Kennelly, 1984). In fact, the benefits of choline in reducing hepatic triacylglycerol (Zenobi et al., 2018b) or improving lactation performance in dairy cows (Bollatti et al., 2018; Zenobi et al., 2018a) have been observed in diets balanced for methionine.

Based on the importance of choline, dietary requirements have been established for several farm animal species (i.e., poultry, swine, and fish); however, to our knowledge no choline requirement has been established for adult dairy cattle (NRC, 2001). An impediment to establishing requirements is that choline needs to be supplemented as RPC because of extensive microbial degradation (Sharma and Erdman, 1989a). This can potentially create variability in animal response because bioavailability of choline likely differs in different products or methods of protection. Indeed, the intestinal supply of choline or its bioavailability has been poorly described in the literature. de Veth et al. (2016) showed a large linear increase in portal net flux of choline biomolecules with increasing dose of abomasally infused choline chloride; however, the relative bioavailability of choline in RPC in the same experiment was $13 \%$ of that of abomasally infused. We showed that production responses to feeding choline increased in a linear fashion as the amount of choline ion increased. Current results suggest that the optimum amount of choline ion to be supplemented to transition cows is at least $25.2 \mathrm{~g} / \mathrm{d}$. This value is based on the upper level of choline present in the database. It is possible that the optimum amount varies with changes in bioavailability from different RPC sources.

The data presented in this meta-analysis included experiments with parous dairy cows. Our search of the published literature identified a paucity of experiments reporting data in which nulliparous cows were supplemented with choline. Only 3 experiments, 2 of which only published as part of a dissertation, were identified and not all 3 experiments reported all responses evaluated in this meta-analysis. The lack of sufficient data precluded any assessment of the effects of choline on performance and health of nulliparous cows. These findings highlight the need for experiments with multiple doses of choline ion in the diet of transition nulliparous dairy cows.

\section{CONCLUSIONS}

The present meta-analysis demonstrated that parous transition dairy cows benefit from diets supplemented with choline. Supplementing choline in a rumen-protected form increased yields of milk, ECM, fat, protein, and tended to reduce the risk of retained placenta and mastitis. Nevertheless, responses to choline for yields of milk, ECM, protein, and efficiency were influenced by the concentration of metabolizable methionine in the MP consumed by cows postpartum. As methio- 
nine increased as proportion of MP, the response to choline decreased suggesting some interplay between the 2 nutrients. Production responses to choline were linear, thereby suggesting that the optimum amount of choline ion to be supplemented to transition cows remains unknown, but likely it is more than the 12.9 $\mathrm{g} / \mathrm{d}$ fed in most experiments evaluated in the current meta-analysis. Although, it is often suggested that choline should be fed to transition cows because of its role in reducing hepatic triacylglycerol content, such response was not observed in the present study. It is possible that the improvements in ECM and feed efficiency masked the role of choline in reducing hepatic triacylglycerol in dairy cows. Finally, the meta-analysis identified lack of enough data to understand the role of supplemental choline in nulliparous cows.

\section{ACKNOWLEDGMENTS}

The authors thank the researchers who provided detailed data not available in the published manuscripts. The assistance of Gabriel G. C. Godoy (São Paulo State University) with data extraction is greatly appreciated.

\section{REFERENCES}

Artegoitia, V. M., J. L. Middleton, F. M. Harte, S. R. Campagna, and M. J. De Veth. 2014. Choline and choline metabolite patterns and associations in blood and milk during lactation in dairy cows. PLoS One 9:e103412.

Baldi, A., and L. Pinotti. 2006. Choline metabolism in high-producing dairy cows: Metabolic and nutritional basis. Can. J. Anim. Sci. 86:207-212.

Bobe, G., J. W. Young, and D. C. Beitz. 2004. Invited review: Pathology, etiology, prevention, and treatment of fatty liver in dairy cows. J. Dairy Sci. 87:3105-3124.

Bollatti, J. M., M. G. Zenobi, N. A. Artusso, G. F. Alfaro, A. M. Lopez, B. A. Barton, J. E. P. Santos, and C. R. Staples. 2018. Timing of initiation and duration of feeding ruminally protected choline (RPC) affects performance of lactating Holstein cows. J. Dairy Sci. 101(E-Suppl. 1):202. (Abstr.)

Braun, A., I. Treede, and D. Gotthardt. 2009. Alternations of phospholipid concentration and species composition of the intestinal mucus barrier in ulcerative colitis: A clue to pathogenesis. Inflamm. Bowel Dis. 15:1705-1720.

Chandler, T. L., and H. M. White. 2017. Choline and methionine differentially alter methyl carbon metabolism in bovine neonatal hepatocytes. PLoS One 12:e171080.

Cooke, R. F., N. Silva del Rio, D. Z. Caraviello, S. J. Bertics, M. H. Ramos, and R. R. Grummer. 2007. Supplemental choline for prevention and alleviation of fatty liver in dairy cattle. J. Dairy Sci. 90:2413-2418.

Davidson, S., B. A. Hopkins, J. Odle, C. Brownie, V. Fellner, and L. W. Whitlow. 2008. Supplementing limited methionine diets with rumen-protected methionine, betaine, and choline in early lactation Holstein cows. J. Dairy Sci. 91:1552-1559.

de Veth, M. J., V. M. Artegoitia, S. R. Campagna, H. Lapierre, F. Harte II, and C. L. Girard. 2016. Choline absorption and evaluation of bioavailability markers when supplementing choline to lactating dairy cows. J. Dairy Sci. 99:9732-9744.

Deuchler, K. N., L. S. Piperova, and R. A. Erdman. 1998. Milk choline secretion as an indirect indicator of postruminal choline supply. J. Dairy Sci. 81:238-242.
Drackley, J. K. 1999. Biology of dairy cows during the transition period: The final frontier? J. Dairy Sci. 82:2259-2273.

Elek, P., J. R. Newbold, I. Gaal, L. Wagner, and F. Husveth. 2008. Effects of rumen-protected choline supplementation on milk production and choline supply of periparturient dairy cows. Animal 2:1595-1601.

Emmanuel, B., and J. J. Kennelly. 1984. Kinetics of methionine and choline and their incorporation into plasma lipids and milk components in lactating goats. J. Dairy Sci. 67:1912-1918.

Erdman, R. A., and B. K. Sharma. 1991. Effect of dietary rumen-protected choline in lactating dairy cows. J. Dairy Sci. 74:1641-1647.

Erdman, R. A., R. D. Shaver, and J. H. Vandersall. 1984. Dietary choline for the lactating cow: Possible effects on milk fat synthesis. J. Dairy Sci. 67:410-415.

Hartwell, J. R., M. J. Cecava, and S. S. Donkin. 2000. Impact of dietary rumen undegradable protein and choline on intake, peripartum liver triglyceride, plasma metabolites and milk production in dairy cows. J. Dairy Sci. 83:2907-2917.

Imhasly, S., C. Bieli, H. Naegeli, L. Nyström, M. Ruetten, and C. Gerspach. 2015. Blood plasma lipidome profile of dairy cows during the transition period. BMC Vet. Res. 11:252.

Kinsella, J. 1969. Biosynthesis of choline-containing lipids by ruminant mammary tissue. J. Dairy Sci. 52:1875-1877.

Kvidera, S. K., E. A. Horst, M. V. Sanz Fernandez, M. Abuajamieh, S. Ganesan, P. J. Gordon, H. B. Green, K. M. Schoenberg, W. E. Trout, A. F. Keating, and L. H. Baumgard. 2017. Characterizing effects of feed restriction and glucagon-like peptide 2 administration on biomarkers of inflammation and intestinal morphology. J. Dairy Sci. 100:9402-9417.

Lean, I. J., A. R. Rabiee, T. F. Duffield, and I. R. Dohoo. 2009. Invited review: Use of meta-analysis in animal health and reproduction: Methods and applications. J. Dairy Sci. 92:3545-3565.

Lima, F. S., M. F. Sá Filho, L. F. Greco, and J. E. P. Santos. 2012. Effects of feeding rumen-protected choline on incidence of diseases and reproduction of dairy cows. Vet. J. 193:140-145.

Martinez, N., L. D. Sinedino, R. S. Bisinotto, E. S. Ribeiro, G. C. Gomes, F. S. Lima, L. F. Greco, C. A. Risco, K. N. Galvão, D. Taylor-Rodriguez, J. P. Driver, W. W. Thatcher, and J. E. P. Santos. 2014. Effect of induced subclinical hypocalcemia on physiological responses and neutrophil function in dairy cows. J. Dairy Sci. 97:874-887.

Moher, D., A. Liberati, J. Tetzlaff, and D. G. Altman. 2009. The PRISMA Group. Preferred reporting items for systematic reviews and meta-analyses: The PRISMA statement. PLoS Med. 6:e1000097.

Mohsen, M. K., H. M. A. Gaafar, M. M. Khalafalla, A. A. Shitta, and A. M. Yousif. 2011. Effect of rumen protected choline supplementation on digestibility, rumen activity and milk yield in lactating Friesian cows. Slovak J. Anim. Sci. 44:13-20.

NRC. 2001. Nutrient Requirements of Dairy Cattle. 7th rev. ed. Natl. Acad. Press, Washington, DC.

Orth, R. 1992. Sample day and lactation report. DHIA 200 Fact Sheet A-2. Mid-States DRPC, Ames, IA.

Piepenbrink, M. S., and T. R. Overton. 2003. Liver metabolism and production of cows fed increasing amounts of rumen-protected choline during the periparturient period. J. Dairy Sci. 86:1722-1733.

Piepho, H. P. 2009. Data transformation in statistical analysis of field trials with changing treatment variance. Agric. J. 101:865-869.

Pinotti, L., A. Campagnolo, F. D'Ambrosio, F. Susca, M. Innocenti, R. Rebucci, E. Fusi, F. Cheli, G. Savoini, V. Dell'Orto, and A. Baldi. 2008. Rumen-protected choline and vitamin E supplementation in periparturient dairy goats: Effects on milk production and folate, vitamin B12 and vitamin E status. Animal 2:1019-1027.

Ramírez de Molina, A., M. Báñez-Coronelo, R. Gutiérrez, A. Rodríguez-González, D. Olmeda, D. Megías, and J. C. Lacal. 2004. Choline kinase activation is a critical requirement for the proliferation of primary human mammary epithelial cells and breast tumor progression. Cancer Res. 64:6732-6739.

Reynolds, C. K., P. C. Aikman, B. Lupoli, D. J. Humphries, and D. E. Beaver. 2003. Splanchnic metabolism of dairy cows during the 
transition from late gestation through early lactation. J. Dairy Sci. $86: 1201-1217$.

Santos, J. E. P., I. J. Lean, H. Golder, and E. Block. 2019. Meta-analysis of the effects of prepartum dietary cation-anion difference on performance and health of dairy cows. J. Dairy Sci. 102:2134-2154.

Sharma, B. K., and R. A. Erdman. 1989a. In vitro degradation of choline from selected feedstuffs and choline supplements. J. Dairy Sci. $72: 2772-2776$

Sharma, B. K., and R. A. Erdman. 1989b. Effects of dietary and abomasally infused choline on milk production responses of lactating dairy cows. J. Nutr. 119:248-254.

Sun, F., Y. Cao, C. Cai, S. Li, C. Yu, and J. Yao. 2016. Regulation of nutritional metabolism in transition dairy cows: Energy homeostasis and health in response to post-ruminal choline and methionine. PLoS One 11:e0160659.

Vailati-Riboni, M., Z. Zhou, C. Jacometo, A. Minuti, E. Trevisi, D. Luchini, and J. J. Loor. 2017. Supplementation with rumen-protected methionine or choline during the transition period influences whole-blood immune response in periparturient dairy cows. J. Dairy Sci. 100:3958-3968.

Wang, M., and B. J. Bushman. 1999. Integrating results through metaanalytic review using SAS software. SAS Institute Inc., Cary, NC.

Xu, G. Z., J. Ye, J. X. Liu, and Y. Y. Yu. 2006. Effect of rumen protected choline addition on milk performance and blood metabolic parameters in transition dairy cows. Asian-Australas. J. Anim. Sci. 19:390-395
Yao, Z. M., and D. E. Vance. 1988. The active synthesis of phosphatidylcholine is required for very low-density lipoprotein secretion from rat hepatocytes. J. Biol. Chem. 263:2998-3004.

Zeisel, S. H., and K. A. Da Costa. 2009. Choline: An essential nutrient for public health. Nutr. Rev. 67:615-623.

Zenobi, M. G., R. Gardinal, J. E. Zuniga, A. L. G. Dias, C. D. Nelson, J. P. Driver, B. A. Barton, J. E. P. Santos, and C. R. Staples. 2018a. Effects of supplementation with ruminally protected choline on performance of multiparous Holstein cows did not depend upon prepartum caloric intake. J. Dairy Sci. 101:1088-1110.

Zenobi, M. G. T. L. Scheffler, J. E. Zuniga, M. B. Poindexter, S. R. Campagna, H. F. Castro Gonzalez, A. T. Farmer, B. A. Barton, J. E. P. Santos, and C. R. Staples. 2018b. Feeding increasing amounts of ruminally protected choline decreased fatty liver in nonlactating, pregnant Holstein cows in negative energy status. J. Dairy Sci. 101:5902-5923.

Zhou, Z., M. Vailati-Riboni, E. Trevisi, J. K. Drackley, D. N. Luchini, and J. J. Loor. 2016. Better postpartal performance in dairy cows supplemented with rumen-protected methionine compared with choline during the peripartal period. J. Dairy Sci. 99:8716-8732.

\section{ORCIDS}

C. R. Staples (๑) https://orcid.org/0000-0002-0237-946X

J. E. P. Santos ๑ https://orcid.org/0000-0003-3403-1465 